\title{
Two Concepts or Two Approaches? A Bifactor Analysis of Psychological and Subjective Well-Being
}

\author{
Fang Fang Chen $\cdot$ Yiming Jing $\cdot$ Adele Hayes $\cdot$ Jeong Min Lee
}

(C) Springer Science+Business Media B.V. 2012

\begin{abstract}
Researchers often debate about whether there is a meaningful differentiation between psychological well-being and subjective well-being. One view argues that psychological and subjective well-being are distinct dimensions, whereas another view proposes that they are different perspectives on the same general construct and thus are more similar than different. The purpose of this investigation was to examine these two competing views by using a statistical approach, the bifactor model, that allows for an examination of the common variance shared by the two types of well-being and the unique variance specific to each. In one college sample and one nationally representative sample, the bifactor model revealed a strong general factor, which captures the common ground shared by the measures of psychological well-being and subjective well-being. The bifactor model also revealed four specific factors of psychological well-being and three specific factors of subjective well-being, after partialling out the general well-being factor. We further examined the relations of the specific factors of psychological and subjective well-being to external measures. The specific factors demonstrated incremental predictive power, independent of the general well-being factor. These results suggest that psychological well-being and subjective well-being are strongly related at the general construct level, but their individual components are distinct once their overlap with the general construct of well-being is partialled out. The findings thus indicate that both perspectives have merit, depending on the level of analysis.
\end{abstract}

Keywords Bifactor model - Second-order factor model - Psychological well-being · Subjective well-being · Positive and negative affect · Life satisfaction · Personality

F. F. Chen $(\bowtie) \cdot$ Y. Jing $\cdot$ A. Hayes $\cdot$ J. M. Lee

Department of Psychology, University of Delaware, Wolf Hall, Newark, DE 19716, USA

e-mail: xiyu@ @sych.udel.edu

Y. Jing

e-mail: yjing@psych.udel.edu

A. Hayes

e-mail: ahayes@psych.udel.edu

J. M. Lee

e-mail: jlee@psych.udel.edu 


\section{Introduction}

Two different views have been advanced with regard to the study of well-being and its role in the psychological domains of cognition, emotion, and motivation. The subjective wellbeing perspective (SWB) focuses on the hedonic aspect of well-being, which is the pursuit of happiness and a pleasant life. It involves global evaluations of affect and life quality (Diener 1984). The psychological well-being perspective (PWB) focuses on eudaimonic well-being, which is the fulfillment of human potential and a meaningful life. PWB involves perceived thriving in the face of existing challenges of life, such as pursuing meaningful goals, growing and developing as a person, and establishing quality ties to others (Ryff 1989; Ryff and Keyes 1995; Ryff and Singer 2008). The conceptual distinction between these two types of well-being is under debate. One camp argues that SWB and PWB address distinct aspects of well-being, although both are fundamentally concerned with the subjective nature of well-being (Keyes et al. 2002). The other camp proposes that SWB and PWB reflect two research traditions rather than two separate concepts of well-being, as they are more similar than different from each other (Kashdan et al. 2008).

The overarching goal of this paper is to examine these theoretical claims by using a bifactor modeling approach (Chen et al. 2006, 2012; Gustafsson and Balke 1993; Reise et al. 2007; Rindskopf and Rose 1988), which can estimate a general well-being factor shared by the two types of well-being, as well as the unique contributions of SWB and PWB in predicting outcome measures. If SWB and PWB are independent factors and can differentially predict external variables, beyond the shared variance with the general wellbeing construct, it is likely that SWB and PWB are two related yet distinct concepts. On the other hand, if either SWB or PWB do not form an independent factor after taking into account the shared common variance, it casts doubt on the conceptual uniqueness of these two types of well-being.

\section{Theories of Well-Being}

Hedonic theories of well-being have been the most extensively studied models of wellbeing. Exemplifying the hedonic tradition, researchers such as Flugel (1925) and Bradburn (1969) examined how people feel as they go about their daily lives. Diener's (1984) review of research on SWB culminated in a model composed of a person's cognitive and affective evaluations of life as a whole. Specifically, Diener considers SWB to be the experience of high levels of pleasant emotions and moods, low levels of negative emotions and moods, and high life satisfaction. In Diener's work, "subjective well-being" is used synonymously with "hedonic well-being" (Diener 1984). In contrast, in the eudaimonic tradition (Waterman 1993), well-being is considered the outcome of positive goal pursuits (Ryan et al. 2008). Building on the relevant work from developmental, humanistic, and clinical psychology, Ryff (1989) proposed a model of psychological (eudaimonic) well-being that includes six related yet distinct components. This model of eudaimonic well-being rests on the assumption that individuals strive to function fully and realize their unique talents. The six dimensions of eudaimonic well-being encompass a breadth of well-being that includes positive evaluation of oneself and one's past (self-acceptance), a sense of continued growth and development as a person (environmental mastery), the belief that one's life is purposeful and meaningful (purpose in life), quality relations with others (positive relations with others), the capacity to manage one's life and surrounding world effectively (personal growth), and a sense of self-determination (autonomy) (Ryff and Keyes 1995; Ryff and 
Singer 2008). Ryff (1989) has further developed a multidimensional scale to measure these components of well-being. However, the discriminant validity of the six dimensions has been questioned. Particularly, the correlations among self-acceptance, environmental mastery, purpose in life, and personal growth are high (e.g., Abbott et al. 2006; Burns and Machin 2009; Clarke et al. 2001; Ryff 1989; Ryff and Keyes 1995).

\section{The Debate on Well-Being: Two Constructs or Two Perspectives?}

Are subjective well-being and psychological well-being two separate constructs or simply two approaches to the study of well-being? One direct way to address this issue is to examine the joint factor structure of SWB and PWB and their differential predictive power. Evidence thus far seems to suggest that SWB and PWB are highly related yet distinct aspects of positive psychological functioning. For example, in a factor analysis of a variety of well-being measures, two correlated factors were found and the factors consisted of SWB (e.g., happiness, life satisfaction) and personal growth (e.g., openness to experience, maturity) (Compton et al. 1996). Another factor analysis also revealed two correlated factors: happiness (including depression, positive affect, and life satisfaction) and meaning (including four of Ryff's 1989 PWB scales: personal growth, purpose in life, positive relations with others, and autonomy). The distinctiveness of the two factors was reflected in the differential association of happiness with goal efficacy, on the one hand, and of meaning with goal integrity, on the other (McGregor and Little 1998). Similarly, a strong correlation between the SWB factor and PWB factor was reported in other studies (Gallagher et al. 2009; Keyes et al. 2002). A moderate correlation between PWB and SWB was found in a recent study. After controlling for personality, PWB remained a significant predictor of SWB (Burns and Machin 2010). In that study, PWB was defined by four highly correlated components of Ryff's scales (i.e., environmental mastery, personal growth, purpose in life, and self-acceptance), because evidence suggests that the factor structure of Ryff's scales is best represented by a super-ordinate factor comprised of these four components and two remaining factors, autonomy and positive social relations (Abbott et al. 2006; Burns and Machin 2009, 2010). Moreover, Burns and Machin (2009) utilized an oblique Principal Axis Factor analysis to examine the factor structure of PSB and SWB, and the results support the distinction between PWB and SWB.

However, the existing studies did not separate the unique variance associated with SWB and PWB from the common variance shared by the well-being measures, which is crucial for clarifying the debate regarding the nature of well-being. Given that SWB and PWB are both concerned with the positive aspect of psychological functioning, it is important to examine the commonality shared by the two types of well-being as well as the distinctive nature of each. The bifactor model becomes an ideal tool for addressing this issue. Conceptually, the bifactor model can provide a synthetic understanding of the relations between SWB and PWB and their associations with important external variables.

\section{Importance of Testing Unique Predictive Power of Individual Facets}

When a construct is comprised of multiple facets, the relations between the construct and outcome measures become complicated. It is important to test the predictive validity of the general construct, as well as the unique functions of the individual facets. Traditionally, researchers have adopted one of two commonly used approaches. The first method is to 
take the sum or average (i.e., form a composite score) of individual facets and then relate the composite score to external variables. However, this approach can lead to conceptual ambiguity, as the composite captures mostly the shared effects but does not separate the unique effect of each facet from the shared variance among the facets. It is possible that the general construct (e.g., general well-being) contributes nothing of its own over and above the individual facets (e.g., SWB and PWB) or vice versa. It is also possible that one facet is responsible for relations with one set of criterion variables, whereas another facet is responsible for relations with a different set of criterion variables. It is even possible for two facets to correlate in opposite directions with criterion variables (e.g., Tett et al. 2003).

The second approach is to relate each of the individual facets, rather than the general construct, to outcome measures. This approach can also lead to conceptual ambiguity, as the specific effects of the facets are often entangled with the effects of the shared general construct (for related discussion, see Briggs and Cheek 1988; Carver 1989; Finch and West 1997; Hull et al. 1991).

Researchers have long recognized the significance of testing multifaceted constructs with an appropriate approach (e.g., Caspi et al. 2005; McCrae and Costa 1992; Ozer and Benet-Martínez 2006). However, there has not been a method that allows us to assess the unique, separate contributions of facets (e.g., SWB and PWB) as well as the general construct (e.g., the general well-being). A bifactor model is particularly well-suited for addressing this issue, as it can separate the unique contributions of the individual facets from the effects of the general construct and test both effects simultaneously (see Chen et al. 2012 for detailed discussion).

\section{The Present Studies: Bifactor Analysis of Well-Being}

The bifactor model has recently been proposed to test constructs that are comprised of multiple related yet distinct facets (Chen et al. 2006, 2012; Reise et al. 2007). A bifactor model tests whether: (a) there is a general factor that accounts for the commonality shared by the facets, and (b) there are multiple specific factors, each of which accounts for the unique influence of the specific facet over and above the general factor. For example, this method can be used to test whether the psychological well-being of Ryff's scale is comprised of six related facets (i.e., autonomy, environmental mastery, personal growth, positive relations with others, purpose in life, and self-acceptance). The bifactor model can reveal whether all six facets contribute to an overarching general psychological well-being factor, and whether each of the facets contributes to a specific factor, stemming from its unique variance over and beyond the general factor (see Fig. 1).

The bifactor model has two central advantages. First, it permits simultaneous tests of the association of an outcome variable with the general latent factor and the unique contributions of the specific factors that are distinct from the general construct. Second, the bifactor model can be used to identify a facet that may no longer remain a unique contributor, after taking into account the common variance shared with other facets. As illustrated below, these unique characteristics of a bifactor model make it particularly suitable for addressing the debate about the relations between subjective well-being and psychological well-being. As a comparison, we describe an alternative model, the secondorder factor model, which is conceptually similar yet functionally different from the bifactor model. 


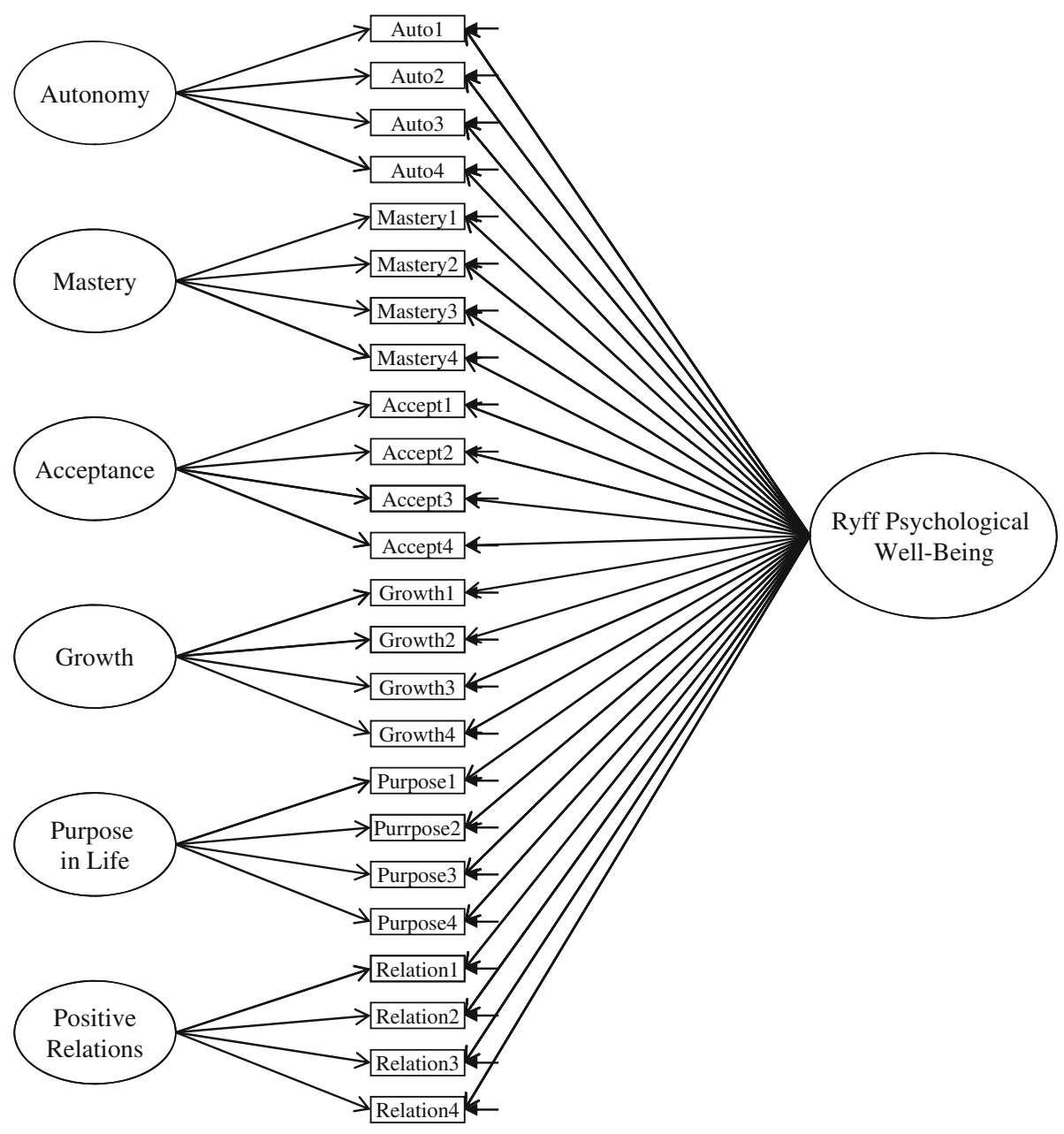

Fig. 1 Conceptual bifactor model of psychological well-being

The second-order model has been widely used in applied research when measurement instruments assess several related facets (e.g., DeYoung et al. 2002; Marsh et al. 2002). In the case of psychological well-being, a second-order model hypothesizes that the six facets consist of the six lower-order factors, and there is a higher-order factor of general psychological well-being that accounts for the commonality shared by the lower-order factors (i.e., the individual facets). The second-order and bifactor models have similar conceptual interpretations (Gustafsson and Balke 1993). The higher-order factor in the second-order model is similar to the general factor in the bifactor model. The disturbances of the firstorder factors in the second-order model resemble the specific factors in the bifactor model. However, the differences between the two models become more important when researchers are also interested in the contribution of one or more of the specific factors over and above the general/second-order factor. Chen et al. $(2006,2012)$ provide a general 
discussion of the advantages of the bifactor model over the second-order model in testing multifaceted constructs.

We briefly introduce the major advantages of bifactor models. First, only bifactor models can separate the specific factors from the general factor. The strength of the relationship between the specific factors and their associated items is reflected in the factor loadings. These relationships cannot be tested in the second-order model, as the specific factors are represented by the unique variances (i.e., disturbances) of the first-order factors. Second, only bifactor models can identity whether a facet still exists after partialling out the general factor. Third, only bifactor models can test mean differences of facets over and above the general factor. In contrast, in the second-order model only the second-order latent means can be directly compared, as the specific factors are represented by disturbances. Fourth, the bifactor model is more applicable when testing whether a subset of the specific factors can predict external variables over and above the general factor, as the specific factors are directly represented as independent factors rather than disturbances as in second-order models. In second-order models, specific factors (disturbances) may also be used to predict external criteria, over and above the second-order factor, but such tests may require the use of non-standard structural equation models (SEM). That is, the disturbances of the first-order factors will be used as predictors. However, such non-standard models are not easily implementable in many of the standard structural equation modeling software packages, such as Mplus and LISREL. Results from such non-standard models may be difficult to explain to researchers who are more familiar with the ideal that latent factors, not disturbances, can be used as predictors in SEM. Finally, only bifactor models can be applied when a construct is comprised of two facets. Second-order models cannot be identified because they require at least three facets. ${ }^{1}$

In two studies, we examined the relations between PWB and SWB. A bifactor model tests whether: (1) there is a general factor, which can be labeled Global Well-Being, that accounts for the common ground shared by PWB and SWB, and (2) there are several specific factors, each of which accounts for unique variance, over and above the general factor. Importantly, the specific factors in this model would be independent of each other, as they capture the unique variance of PWB and SWB, and they are also independent of the general well-being factor, which is partialled out.

If SWB and PWB are indeed different constructs (Keyes et al. 2002), the two types of well-being would form a general factor, given that both are related to the positive nature of well-being, but their components would also form strong specific factors with unique predictive power, over and above the general well-being factor. On the other hand, if SWB and PWB reflect two theoretical perspectives rather than two distinct constructs (Kashdan et al. 2008), they would form a strong general factor, but the residual variance of SWB and/ or PWB would not form strong specific factors, as their variances would be largely explained by the general factor.

We further investigated whether the specific factors of PWB and SWB were associated with external variables, over and above the general factor of global well-being. In Study 1, the external variables included measures that have been associated with well-being, such as relationship quality, social support, optimism, self-enhancement, depressive symptoms, and the importance of aspirations. In Study 2, the external measures included self-esteem, optimism, and depressed mood, personality, locus of control, social relationships, and

\footnotetext{
1 The second-order models with two facets can be identified if the 'loadings' (i.e., latent regression paths) of the second-order factor are constrained equally, or if the factor has estimated correlations with other factors in the model (paralleling the identification of lower-order constructs with two indicators).
} 
religiosity (Lucas et al. 1996; Ryan and Deci 2001; Ozer and Benet-Martínez 2006; Ryff and Singer 2006). This study is not meant to be a comprehensive review of the literature on the relations between well-being and external variables, but rather is a starting point to introduce the bifactor model as a possible tool with which to address theoretical and empirical issues in well-being research.

\section{Study 1 Method}

\subsection{Participants}

The participants were 795 undergraduate introductory psychology students (356 men and 439 women) at the University of Delaware. The mean age of the sample was 19.27 ( $S D=$ $1.78)$.

\subsection{Well-Being Measures}

\subsubsection{Psychological Well-Being (PWB)}

The construct was measured by Ryff's (1989) multidimentional inventory of PWB, which assesses the goal of reaching human potential and having a meaningful life. The 54-item scale includes six components: self-acceptance $(\alpha=.77)$, environmental mastery $(\alpha=.80)$, purpose in life $(\alpha=.77)$, positive relations with others $(\alpha=.74)$, personal growth $(\alpha=.78)$, and autonomy $(\alpha=.87)$.

\subsubsection{Subjective Well-being (SWB)}

The SWB scales are designed to measure global evaluations of affect and life quality. SWB has three major components, including two affective dimensions (i.e., positive affect and negative affect) and one cognitive dimension (i.e., life satisfaction). Affect was assessed using the Positive and Negative Affect Schedule (PANAS; Watson et al. 1988). The Positive affect scale consists of active, alert, attentive, determined, enthusiastic, excited, inspired, interested, proud, and strong $(\alpha=.87)$ The Negative affect scale is comprised of afraid, ashamed, distressed, guilty, hostile, irritable, jittery, nervous, scared, and upset $(\alpha=.87)$. Participants rated the extent to which they had felt each of the affects "during the past few days".

Life satisfaction was assessed with the Satisfaction with Life Scale (Diener et al. 1985). This 5-item scale measures life satisfaction as a cognitive-judgmental process by asking a person to provide an overall judgment of their quality of life. Cronbach's alpha for this scale was .89 .

\subsection{External Variables}

\subsubsection{Rosenberg Self-Esteem (Rosenberg 1965)}

This commonly used scale measures global view of the self. Cronbach's alpha for this scale was .91. 


\subsubsection{Optimism (Marshall et al. 1992)}

This scale assesses the extent to which individuals possess hope and favorable expectations regarding life outcomes. Cronbach's alpha was .82 .

\subsubsection{Relationship Quality (Kang and Shaver 2004)}

The Interpersonal Relationship Quality scale assesses individual differences in the quality of relationships with others. Cronbach's alpha for this scale was .88 .

\subsubsection{Social Support}

Social support was measured by the Social Provision Scale (Cutrona and Russell 1987), which assesses multiple dimensions of perceived support from one's social relationships. Cronbach's alphas for the 6 subscales were $.84, .76, .87, .68, .83$, and .73 .

\subsubsection{Self-Enhancement}

The scale consists of 16 positive adjectives, including attractive, interesting, independent, confident, intelligent, unique, creative, competent, cooperative, loyal, considerate, selfsacrificing, likable, modest, agreeable, and compromising selected from previous research (Gaertner et al. 2008; Markus and Kitayama 1991). Participants were asked to compare themselves with a typical student of the same age and same gender as they were. Cronbach's alpha was .92 .

\subsubsection{Beck Depression Inventory-II (BDI-II)}

This scale assesses the severity of self-reported depression in both clinical and non-clinical samples. These symptoms fall into three related factors: negative attitudes, performance difficulties, and somatic complaints (Beck et al. 1996). Cronbach's alphas for the subscales were $.89, .82$, and .74 .

\subsubsection{Aspiration Index}

This scale assesses the importance of various extrinsic and intrinsic goals within an individual's personal goal system (Grouzet et al. 2005; Kasser and Ryan 1993, 1996). We selected five goal domains from the original scale: financial success, self-acceptance, affiliation, community feeling, and physical health. The relative importance of each goal domain was computed by subtracting the total score from the score of each goal domain (Grouzet et al. 2005).

\section{Study 1 Results and Discussion}

\subsection{Model Testing Stages}

The analyses involved two steps. First, a bifactor model was tested for psychological wellbeing and subjective well-being, respectively. Second, given adequate model fit for each type of well-being, a final bifactor model was tested in which psychological and subjective 
well-being were combined to form a general well-being factor. For comparison purposes, a second-order factor model was tested for the combined psychological and subjective wellbeing. Analyses were conducted using Mplus software 5.0 (Muthén and Muthén 19982009). Given that the model involves a total of 79 items (54 items for PWB and 25 items for SWB), random parcels were created by aggregating two items ${ }^{2}$ in each indicator. Parcels have several advantages over analyzing items in confirmative factor analysis when a measure is comprised of many items. Parcels often provide a closer approximation of normally distributed variables, have higher reliabilities, have a lower ratio of observed variables to latent constructs, which makes the model more stable and parsimonious, and can improve model fit (Bagozzi and Edwards 1998; Hall et al. 1999; Little et al. 2002). However, the factors extracted from such data could arguably be second-order factors rather than first-order factors. This is because some or all of the items being analyzed are essentially 'composite' items or variables that are created to simplify the set of variables being put into the analysis. The implications of item parcelling for the results of factor analytic procedures are discussed at some length by Kline (2011).

\subsection{Testing Psychological Well-Being}

\subsubsection{A Bifactor Model of Psychological Well-Being}

A preliminary six-factor $\mathrm{CFA}^{3}$ based on the six dimensions of Ryff's PWB scale indicated that purpose in life and personal growth were highly correlated $(r=.90)$, as were environmental mastery and self-acceptance $(r=.94)$. The correlations among other facets ranged from .63 to .85 , which formed the foundation for a bifactor model. It was thus expected that responses to the psychological well-being items could be explained by one general factor that captures the commonality shared by the six subscales, plus four, rather than six, specific factors (autonomy, environmental mastery/self-acceptance, personal growth/purpose in life, and positive relations) over and above the general factor. That is, environmental mastery and self-acceptance would form one specific factor, termed mastery/acceptance, and personal growth and purpose in life would also form one specific factor, termed growth/purpose, given the high correlation within the pairs (Fig. 2).

The model fit the data adequately, $\chi^{2}=1242.25(d f=228, N=795)$, RMSEA $=.075$ (CI: .071 to .079$),$ SRMR $=.045$, and CFI $=.908$. However, two indicators of the personal growth facet had very strong loadings on the general factor but near zero loadings on their specific factor, and their residual variance was negative. This suggests that the variances of the two indicators were entirely explained by the general factor. The bifactor model was then modified by removing the two indicators from the specific factor. The modified model fit the data adequately, $\chi^{2}=1259.19(d f=230, N=795)$, RMSEA $=$ .075 (CI: .071 to .079$)$, SRMR $=.045$, and $\mathrm{CFI}=.907$. There were no appreciable changes in RMSEA (.075 vs. .075), SRMR (.045 vs. .045), and CFI (.908 vs. .907) between the two models. The Chi-square difference was trivial, $\Delta \chi^{2}=16.94(\Delta d f=2, N=795)$, given the large sample size.

In general, the items had stronger loadings on the general factor than on the specific factors, suggesting that most of their variances were shared with the general factor and that

\footnotetext{
${ }^{2}$ For each component of PWB, three two-item parcels and one three-item parcel were created, resulting 4 parcels per component.

${ }^{3}$ The six-factor model fit the data on the borderline, $\chi^{2}=1390.50(d f=237, N=795)$, RMSEA $=.078$ (CI: .074 to .082), SRMR $=.047$, and CFI $=.895$.
} 


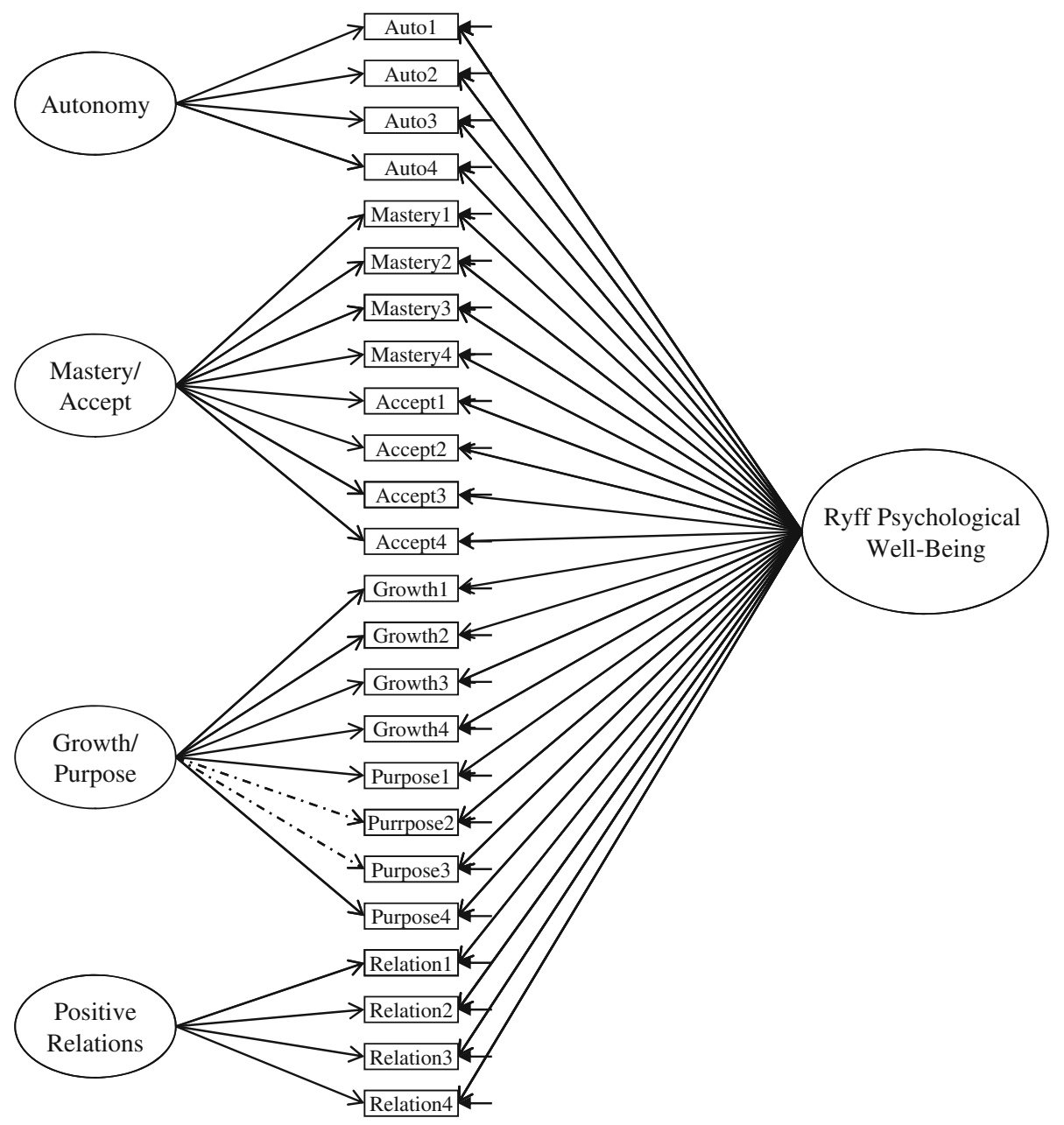

Fig. 2 Tested bifactor model of psychological well-being (Study 1). The dotted line represents a nonsignificant loading

their specific factors were relatively weak. However, items of autonomy loaded equally strongly on the general factor and its specific factor, suggesting that its variance was split between the general factor and the specific factor, and thus more distinct from other components.

\subsubsection{Second-Order Factor Models of Psychological Well-Being}

We first tested a full second-order model with all six components included as the lowerorder factors, and then tested a competing second-order model identified in previous studies (Abbott et al. 2006; Burns and Machin 2009, 2010). In this competing model, the second-order factor consisted of four components (i.e., environmental mastery, selfacceptance, personal growth and purpose in life) and the other two components (i.e., autonomy and positive relations with others) were included as correlated factors. 
The full second-order model fit the data on the borderline, $\chi^{2}=1509.73(d f=246$, $N=795)$, RMSEA $=.080(\mathrm{CI}: .077$ to .084$)$, SRMR $=.050$, and CFI $=.885$. All six components loaded strongly on the second-order factor. The standardized factor loadings were $.65, .92, .89, .92, .99$, and .94 for autonomy, environmental mastery, personal growth, positive relations, purpose in life and self-acceptance, respectively, indicating that all six components share the common ground of PWB. Consistent with the results from the bifactor model, autonomy was more distinct from other components of PWB, as indicated by its relatively lower loading on the second-order factor.

The competing second-order model also fit the data on the borderline, $\chi^{2}=1486.43$ $(d f=245, N=795)$, RMSEA $=.080$ (CI: .076 to .084$),$ SRMR $=.048$, and CFI $=.887$. All four components loaded strongly on the second-order factor, and the standardized factor loadings were $.92, .89, .98$, and .94 for environmental mastery, personal growth, purpose in life and self-acceptance, respectively. However, the second-order factor was strongly correlated with autonomy $(r=.67)$ and with positive relations $(r=.93)$. Although the competing second-order model was less stringent than the full second-order factor model, it did not fit the data significantly better. Specifically, there were no appreciable changes in RMSEA (.080 vs. .080), SRMR (.050 vs. .048), and CFI (.887 vs. $.887)$. The Chi-square difference was trivial, $\Delta \chi^{2}=23.30(\Delta d f=1, N=795)$, given the large sample size. These results suggest that a full second-order model should be retained.

\subsection{Testing Subjective Well-Being}

\subsubsection{A Bifactor Model of Subjective Well-Being}

It was expected that responses to subjective well-being could be explained by one general factor that captures the commonality shared by PANAS positive affect, PANAS negative affect, and life satisfaction, plus three specific factors-termed positive affect, negative affect, and life satisfaction-over and above the general factor (Fig. 3). The model fit the data adequately, $\chi^{2}=251.24(d f=75, N=795)$, RMSEA $=.054$ (CI: .047 to .062$)$, $\mathrm{SRMR}=.026$, and $\mathrm{CFI}=.974$.

In general, the items had stronger loadings on the general factor than on the specific factors, suggesting that most of their variances were shared with the general factor and that their specific factors were relatively weak, as was the case for the measure of psychological well-being. However, items of negative affect loaded more strongly on its specific factor than on the general factor, indicating that most of its variance was not shared with the general factor and thus this facet was more distinct from positive affect and life satisfaction.

\subsubsection{A Second-Order Factor Model of Subjective Well-Being}

The second-order factor model of subjective well-being consisted of one second-order factor and three lower-order factors, PANAS positive affect, PANAS negative affect, and life satisfaction. The model fit the data adequately, $\chi^{2}=332.19(d f=87, N=795)$, RMSEA $=.060$ (CI: .053 to .066$)$, SRMR $=.038$, and CFI $=.964$. All three components loaded strongly on the second-order factor. The standardized factor loadings were .79, -.59 , and .86 for positive affect, negative affect, and life satisfaction, respectively, suggesting that there was a higher-order factor that represented the commonality shared by the components. Nevertheless, consistent with the result from the bifactor model, negative affect was more distinct from the other components of SWB. The corresponding bifactor 


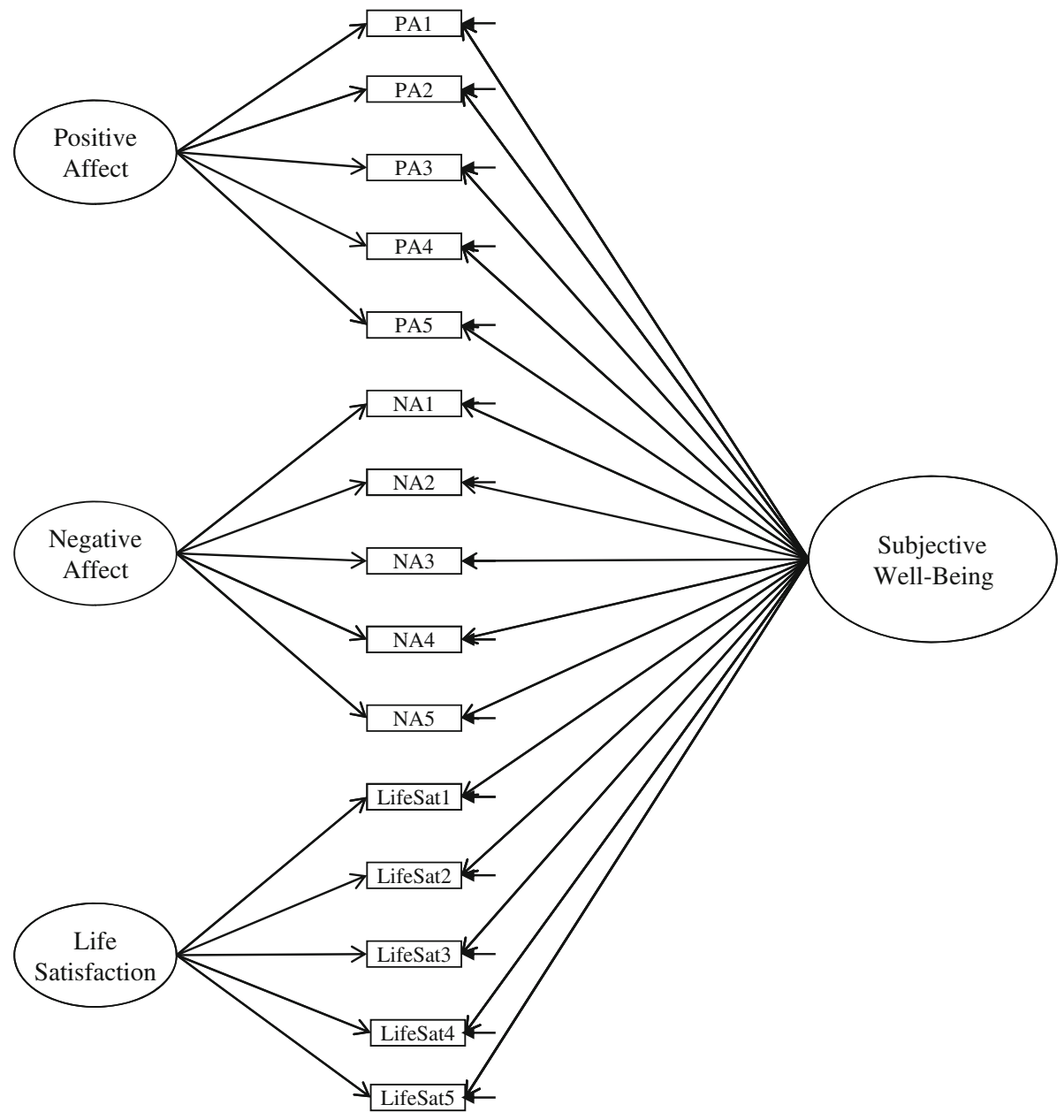

Fig. 3 Tested bifactor model of subjective well-being (Study 1). The dotted line represents a nonsignificant loading

model fit the data better than the second-order model, as there were changes in RMSEA (.060 vs. .054), SRMR (.038 vs. .026), and CFI (.964 vs. .974), and the Chi-square difference was not trivial, $\Delta \chi^{2}=80.95, p<.001(\Delta d f=12, N=795)$.

\subsection{Testing a Bifactor Model of Psychological and Subjective Well-Being}

To test the two different views on the nature of PWB and SWB, we combined the psychological and subjective well-being items into an overall bifactor well-being model (Fig. 4). If PWB and SWB are essentially one construct, responses to the well-being items should be explained by one general factor (termed Global Well-Being) that captures the commonality shared by PWB and SWB. There would be no specific factors. However, if PWB and SWB are two related yet distinct constructs, the subscales should form specific factors independent of the general factor. Based on the above separate analysis of PWB 


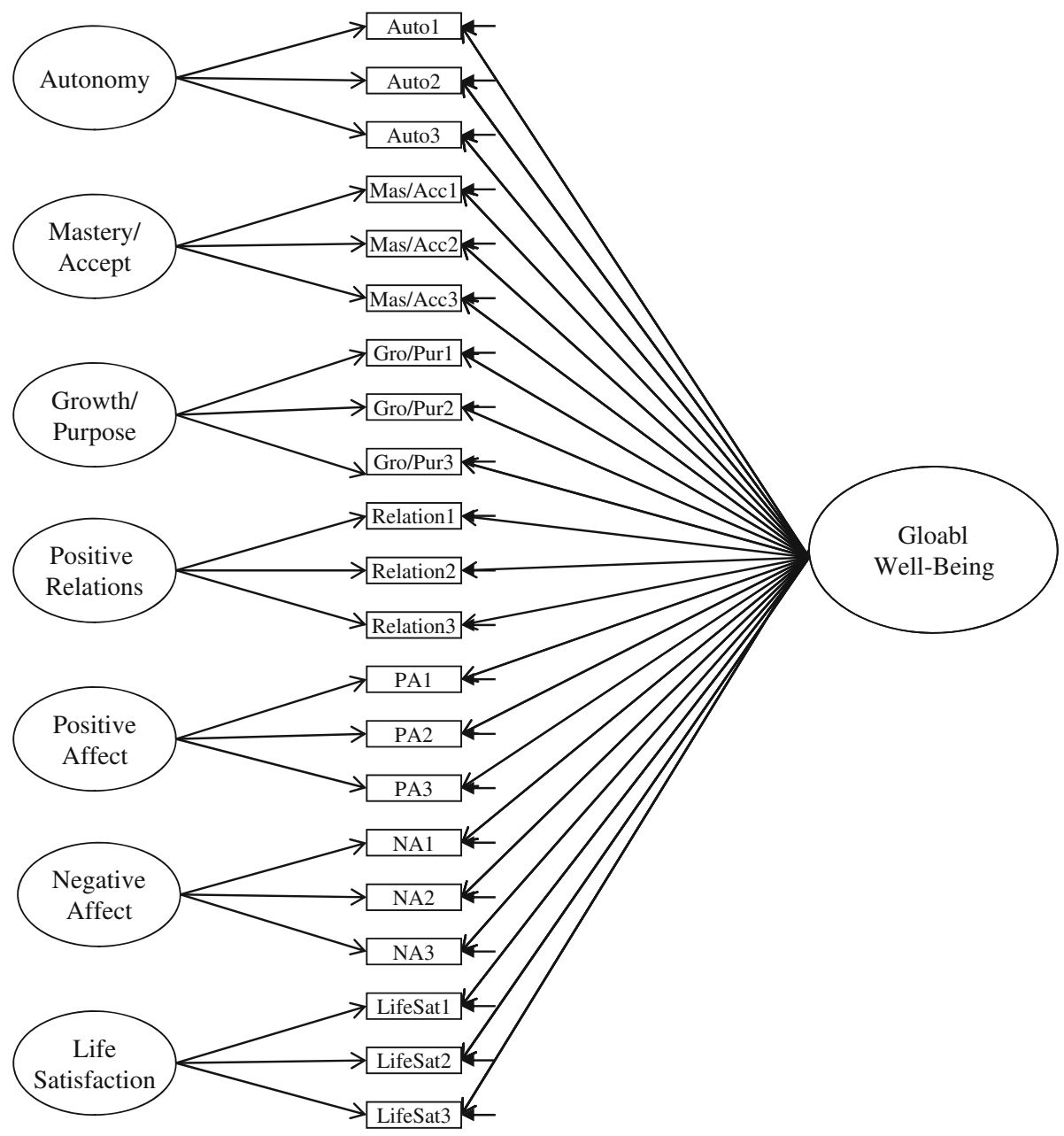

Fig. 4 Conceptual bifactor model of psychological and subjective well-being (Studies 1 and 2)

and of SWB, the bifactor model included four specific factors of PWB (autonomy, environmental mastery/self-acceptance, personal growth/purpose in life, and positive relations), and three specific factors of SWB (positive affect, negative affect, and life satisfaction). The bifactor model fit the data adequately, $\chi^{2}=2624.45(d f=667, N=$ 795), RMSEA $=.061$ (CI: .058 to .063$)$, SRMR $=.051$, and CFI $=.900$.

In general, the items had stronger loadings on the general factor than on the specific factors, suggesting that most of their variances were shared with the general factor. However, items of autonomy and negative affect loaded equally strong on the general factor and their specific factor, suggesting that their variances were split between the general factor and their specific factor, and thus these two facets were more distinct from other components. 


\subsection{Testing a Second-Order Model of Psychological and Subjective Well-Being}

The corresponding second-order model tested whether responses to the items from the psychological and subjective well-being scales could be explained by four-lower order factors of PWB and three-lower order factors of SWB, and there was a higher-order factor that accounted for the variance shared by the lower-order factors. The model fit the data on the borderline, $\chi^{2}=2951.26(d f=694, N=795)$, RMSEA $=.064$ (CI: .062 to .066), $\mathrm{SRMR}=.071$, and $\mathrm{CFI}=.885$.

The bifactor models fit the data significantly better than the second-order model, $\Delta \chi^{2}=326.81(\Delta \mathrm{df}=27), p<.001$, and there were also appreciable changes in RMSEA (.061 vs. .064), SRMR (.051 vs. .071), and CFI (.900 vs. .885), suggesting that the bifactor model provided a better approximation to the data than the second-order model.

\subsection{Relations of General and Specific Factors of Well-Being to External Variables}

To examine whether the specific factors were uniquely associated with outcome variables beyond the general factor, the general and specific factors were used to predict the outcome variables simultaneously in the bifactor models, controlling for age and gender. This analysis included both the bifactor measurement model and structural model in which the predictive relations were tested. All outcome variables were treated as observed variables. The approach of using observed outcome variables allowed us to focus on the bifactor model and its relations to external variables, rather than any possible issues introduced by the measurement model of the external variables. The standardized coefficients are presented in Table 1.

\subsubsection{Well-Being Measures}

The general well-being factor was related to all measures of positive well-being: selfesteem, optimism, relationship quality, social support, and self-enhancement. Over and above the general well-being factor, autonomy was related to self-enhancement; growth/ purpose was related to optimism, relationship quality, social support, and self-enhancement; positive relations was related to self-esteem, relationship quality, social support, and self-enhancement; positive affect was related to optimism, relationship quality, and selfenhancement; negative affect was inversely related to self-esteem; and life satisfaction was related to optimism and relationship quality. In addition, general well-being was inversely related to depressive symptoms. Positive affect and negative affect were also related to depressive symptoms, although the link appeared to be stronger with negative affect.

These findings are consistent with the literature that self-esteem, optimism, relationship quality, social support, and self-enhancement are beneficial to well-being, whereas depression is detrimental to well-being (Lucas et al. 1996; Ryan and Deci 2001; Ozer and Benet-Martínez 2006; Ryff and Singer 2006). Moreover, the relations of specific domains of well-being to well-being related measures are generally in the expected direction. For instance, we found that positive relations was positively associated with self-enhancement, over and above the general well-being factor. This is consistent with Taylor et al.'s (2003) finding that, in Western cultures self-enhancement is associated with a more favorable social impact on others, and can thereby foster positive relations with others. In addition, we found that autonomy was positively associated with self-enhancement, over and above general well-being. This is consistent with a longstanding argument in cultural psychology that self-enhancement is a quality valued in individualistic cultures (Heine and Lehman 1997). 


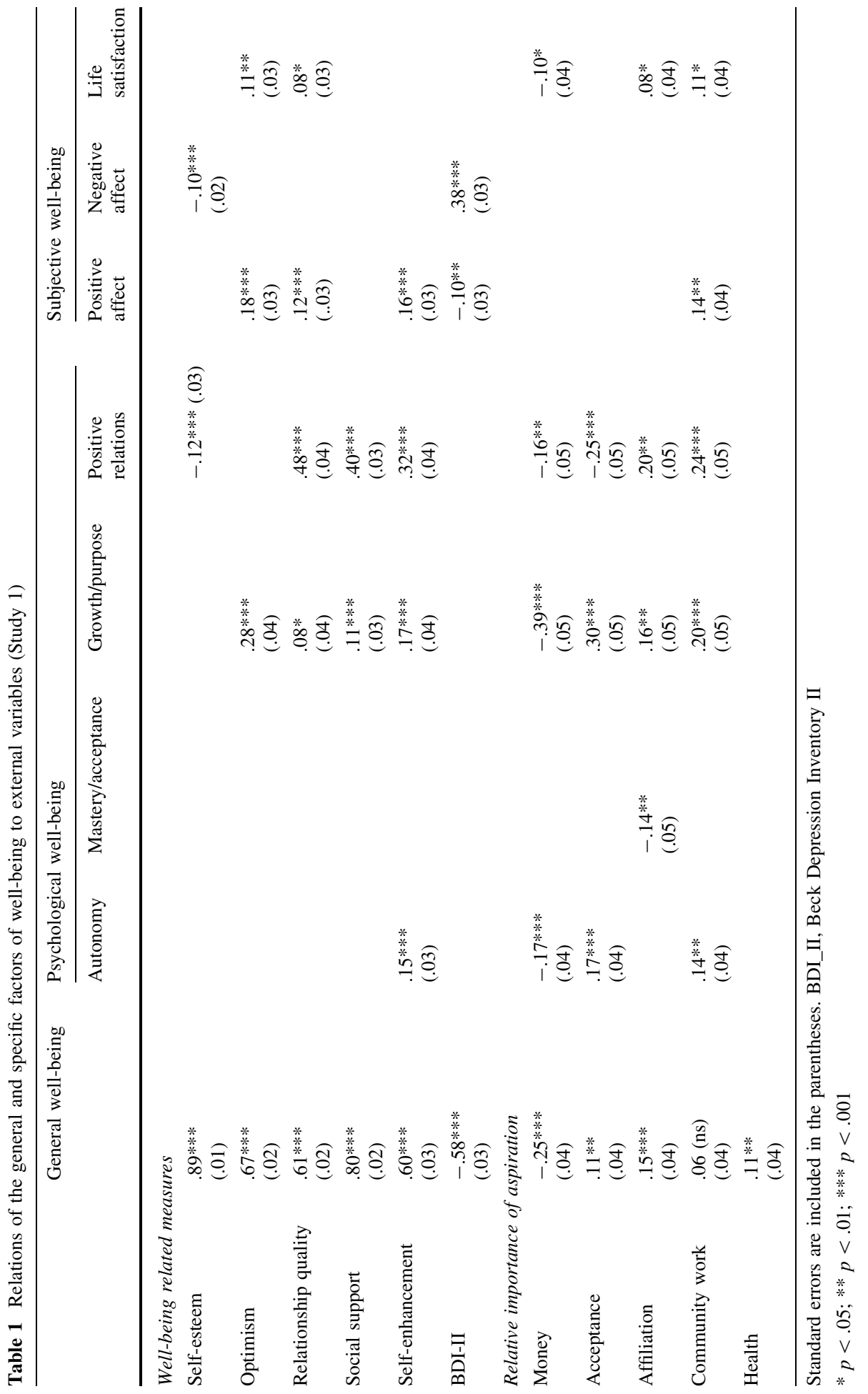




\subsubsection{Relative Importance of Goal Aspiration}

The general well-being factor was related to the relative importance of acceptance, affiliation, and health, but unrelated to the relative importance of community work, and negatively correlated with the relative importance of money. Controlling for the general well-being factor, autonomy was related to acceptance and community work, but negatively related to money; mastery/acceptance was negatively related to affiliation; growth/purpose and positive relations were related to affiliation, and community work, but negatively related to acceptance and money; positive affect was related to community work; and life satisfaction was related to affiliation and community work, but negatively related to money. These results are generally consistent with the literature in that relative importance of acceptance, affiliation and community work are significantly associated with higher well-being, but relative importance of money is associated with lower well-being (Kasser 2002; Kasser and Ryan 1993, 1996).

\section{Study 2 Method}

\subsection{Participants}

The participants were 4032 adult Americans (1,794 men) from the second wave of the National Survey Midlife Development in the United States (MIDUS-II). The purpose of the MIDUS project was to examine the psychological, behavioral, and physical factors that influence healthy aging in a nationally representative sample of adults between the ages of 25 and 74. The original survey was conducted in 1994, and MIDUS-II was a follow-up of these participants from 2004 to 2006 with more reliable measures of well-being. The mean age of the sample was $56.25(S D=12.39)$.

\subsection{Well-Being Measures}

\subsubsection{Psychological Well-Being (MIDUS-II version)}

PWB was assessed with Ryff's (1989) multidimensional inventory. This 42-item scale includes six dimensions of positive functioning: autonomy $(\alpha=.71)$, environmental mastery $(\alpha=.78)$, personal growth $(\alpha=.75)$, positive relations with others $(\alpha=.78)$, purpose in life $(\alpha=.70)$, and self-acceptance $(\alpha=.84)$.

\subsubsection{Subjective Well-Being}

As in Study 1, SWB consists of three major components, including two affective dimensions (i.e., positive affect and negative affect) and one cognitive dimension (i.e., life satisfaction). Positive affect and negative affect were assessed using the Positive and Negative Affect Schedule (PANAS; Watson et al. 1988) and the Positive and Negative Affect Scale (Mroczek and Kolarz 1998). The PANAS Positive Affect adjectives (4-item) included enthusiastic, attentive, proud, and active $(\alpha=.86)$. The PANAS Negative Affect adjectives (5-item) included afraid, jittery, irritable, ashamed, upset $(\alpha=.80)$. The Positive Affect scale (6-item) consisted of cheerful, in good spirits, extremely happy, calm and peaceful, satisfied, and full of life $(\alpha=.90)$. The Negative Affect scale (6-item) consisted of so sad nothing could cheer you up, nervous, restless or fidgety, hopeless, that everything was an effort, and worthless $(\alpha=.85)$. Participants indicated how much they 
felt the items during the past 30 days on a 5-point scale, ranging from 1 (All the time) to 5 (None of the time).

Life Satisfaction was measured with a 5-item scale, which assesses one's judgment of life overall, work, health, relationship with spouse/partner, and relationship with children (Prenda and Lachman 2001). Participants responded on a scale from 0 (The worst possible) to 10 (The best possible) on items such as, "How would you rate your life overall these days?" Cronbach's alpha was .65.

\subsection{External Variables}

\subsubsection{Self-Esteem}

This scale evaluates how much an individual rated his/her worth and merit (Rosenberg 1965). Cronbach's alpha was .76 for this sample.

\subsubsection{Life Orientation Test (Optimism)}

This scale assesses general expectancies for positive outcomes in life (Scheier and Carver 1985). Cronbach's alpha for this sample was .70.

\subsubsection{Social Well-Being Scale}

This measure assesses an individual's current circumstance and functioning ability in society (Keyes 1998). Cronbach's alphas for this sample were: .64 for social coherence, .75 for social integration, .41 for social acceptance, .70 for social contribution, and .66 for social actualization.

\subsubsection{Somatic Amplification}

This scale assesses individuals' sensitivity to their normal physiologic sensations and responses to neutral stimuli that may not be symptomatic of a disease (Barsky et al. 1988). Cronbach's alpha was .53 for this sample.

\subsubsection{Depression}

This scale assesses how many symptoms of depression an individual experienced during a period of at least two weeks in the past 12 months (Wang et al. 2000). Cronbach's alpha was .48.

\subsubsection{Personality Traits}

Six personality traits were measured using a scale created by Rossi (2001), and the traits were neuroticism $(\alpha=.74)$, extraversion $(\alpha=.76)$, openness $(\alpha=.77)$, conscientiousness $(\alpha=.68)$, agreeableness $(\alpha=.80)$, and agency $(\alpha=.81)$.

\subsubsection{Health Locus of Control}

This scale assesses one's perceived level of internal and external influence in the domain of health (Lachman and Weaver 1998). Alpha coefficients for health locus of control were .74 for self and .14 for others. 


\subsubsection{Personality in Intellectual Aging Contexts}

This scale assesses beliefs and attributions about control over intellectual functioning along with aging process across various situations (Lachman et al. 1982). Cronbach's alpha was .73 for this sample.

\subsubsection{Planning and Making Sense of Past Scale}

This measure assesses future and past-oriented planning style of life management (Prenda and Lachman 2001). Alpha coefficients for self-directedness and planning, live for today, and insight into the past for this sample were $.74, .65$, and .39 , respectively.

\subsubsection{Family to Work Spillover Scale}

This measure assesses the extent to which family life helped or interfered with success at work (Grzywacz 2000). Cronbach alpha for positive and negative family to work spillover was .71 and .80 respectively.

\subsubsection{Friend Support and Strain}

This measure assesses the degree of supportive and negative interactions with friends (Schuster et al. 1990). Cronbach's alphas were .88 for friend support and .79 for friend strain.

\subsubsection{Perceived Inequality in Home}

This scale assesses how much individuals perceived themselves to have less socially desired living environments than others (Ryff et al. 1999). Cronbach's alpha for this sample was .78.

\subsubsection{Personal Beliefs on Neighborhood}

This scale assesses perceived neighborhood quality and health by measuring feelings of trust and safety of the neighborhood (Keyes 1998). Cronbach's alpha for this sample was .64.

\subsubsection{Perceived Daily Discrimination Scale}

The scale assesses day-to-day exposures to major forms of discrimination (Williams et al. 1997). Participants responded to the frequency of incidents. Cronbach's alpha was .92.

\subsubsection{Religiosity}

Five scales were used to assess religiosity and spirituality. The Spirituality scale assesses the importance of spirituality in participants' lives (Garfield et al. 2001). Religious support measures perceived support of the congregation or spiritual community (Fetzer Institute/ National Institute on Aging Working Group 1999). The religious/spiritual coping scale measures how often individuals use religiosity and spirituality as a means of support (Garfield et al. 2001). Daily spiritual experiences assessed daily experience of deep inner feelings (Fetzner Institute/National Institute on Aging Working Group 1999). The Mindfulness scale measure how much individuals experience "a heightened state of 
involvement and wakefulness or being in the present" (Langer and Moldoveanu 2000) because of their religion or spirituality. Cronbach's alphas were as follows: .92 for spirituality, .46 for religious support, .87 for religious coping, .89 for daily spiritual experiences, and .94 for mindfulness.

\section{Study 2 Results and Discussion}

\subsection{Model Testing Stages}

As in Study 1, the analysis proceeded in two stages. First, a bifactor model and secondorder factor model were tested for PWB and SWB, respectively. Second, given adequate model fit for each type of well-being, a final bifactor model was tested in which the PWB and SWB were combined to form a general well-being factor. Again for comparison purposes, a second-order factor model was tested for the combined PWB and SWB. Given that the model involves a total of 68 items (42 items for PWB and 26 items for SWB), random parcels were created by aggregating two items in each indicator to make the model more parsimonious and stable. If a scale has an odd number of items, the item with the highest loading based on preliminary item-level analysis was not parceled.

\subsection{Testing Psychological Well-Being}

\subsubsection{A Bifactor Model of Psychological Well-Being}

As in Study 1, preliminary analysis based on the six-factor $\mathrm{CFA}^{4}$ indicated that purpose in life and personal growth were highly correlated $(r=.92)$, as were environmental mastery and self-acceptance $(r=.95)$. Correlations among the other subscales ranged from .52 to .85. The bifactor model was thus comprised of one general factor that captured the common ground shared by the six subscales and four specific factors-autonomy, environmental mastery/self-acceptance, personal growth/purpose in life, and positive relations.

The model fit the data adequately, $\chi^{2}=4118.93(d f=225, N=4032)$, RMSEA $=$ .066 (CI: .064 to .067 ), SRMR $=.044$, and CFI $=.913$. However, two indicators of environmental mastery and one indicator of acceptance had very strong loadings on the general factor but near zero loadings on their specific factor, and their residual variance was negative as well, indicating that the variances of the these indicators were largely explained by the general factor. The bifactor model was then modified by removing these three indicators from the specific factor. The modified model fit the data adequately, $\chi^{2}=4240.40(d f=228, N=4032)$, RMSEA $=.066$ (CI: .064 to .068$)$, SRMR $=.044$, and CFI $=.910$. There were no appreciable changes in RMSEA (.052 vs. .051), SRMR (.029 vs. .030), and CFI (.982 vs. .982) between the two models. The Chi-square difference was not significant, $\Delta \chi^{2}=2.72, n s(\Delta d f=2, N=4032)$.

As in Study 1, the items had stronger loadings on the general factor than on the specific factors, particularly for mastery/accept and growth/purpose. This suggests that most of their variances were shared with the general factor and that their specific factors were

\footnotetext{
4 The six-factor CFA model fit the data on the borderline, $\chi^{2}=5365.99(d f=237)$, RMSEA $=.074$ (CI: .072 to .075$)$, SRMR $=.048$, and $\mathrm{CFI}=.885$.
} 
relatively weak. Consistent with Study 1, items of autonomy loaded equally strongly on the general factor and its specific factor, suggesting that it was more distinct from other factors.

\subsubsection{Second-Order Models of Psychological Well-Being}

As in Study 1, we first tested a full second-order model with all six components included as the lower-order factors, and then tested a competing second-order model identified in previous studies (Abbott et al. 2006; Burns and Machin 2009, 2010). In this competing model, the second-order factor consisted of four components (i.e., environmental mastery, self-acceptance, personal growth and purpose in life) with the other two components (i.e., autonomy and positive relations) included as correlated factors.

The full second-order model fit the data on the borderline, $\chi^{2}=5,517.19(d f=244$, $N=4,032$ ), RMSEA $=.073$ (CI: .072 to .075$)$, SRMR $=.049$, and CFI $=.882$. All six components loaded strongly on the second-order factor. The standardized factor loadings were $.69, .98, .83, .84, .90$, and .98 for autonomy, environmental mastery, personal growth, positive relations, purpose in life and self-acceptance, respectively, indicating that all six components shared the common ground of PWB. Consistent with the results from the bifactor model, autonomy was more distinct from other components of PWB.

The competing second-order model also fit the data on the borderline, $\chi^{2}=5,483.09$ $(d f=243, N=4,032)$, RMSEA $=.073$ (CI: .072 to .075$),$ SRMR $=.049$, and CFI $=.883$. All four components loaded strongly on the second-order factor, and the standardized factor loadings were $.98, .83, .90$, and .98 for environmental mastery, personal growth, purpose in life and self-acceptance, respectively. However, the second-order factor was strongly correlated with autonomy $(r=.70)$ and with positive relations $(r=.85)$. Although the competing second-order model was less constrained than the full second-order factor model, it did not fit the data significantly better. Specifically, there were no appreciable changes in RMSEA (.073 vs. .073), SRMR (.049 vs. .049), and CFI (.882 vs. .883) between the two models. The Chi-square difference was trivial, $\Delta \chi^{2}=34.10(\Delta d f=1, N=4,032)$, given the large sample size. These results suggest that the full second-order model was a better representation of the data than the competing second-order model.

\subsection{Testing Subjective Well-Being}

\subsubsection{A Bifactor Model of Subjective Well-Being}

The bifactor model of subjective well-being consisted of one general factor that characterized the commonality shared by good mood/PANAS positive affect, bad mood/PANAS negative affect, and life satisfaction, plus three specific factors, termed positive affect, negative affect, and life satisfaction, over and above the general factor.

The model fit the data adequately, $\chi^{2}=607.19(d f=51, N=4,032)$, RMSEA $=.052$ (CI: .048 to .056), SRMR $=.029$, and CFI $=.982$. However, two indicators of good mood had strong loadings on the general factor and near zero loadings on their specific factor. In addition, their residual variance was negative. Together, these findings suggest that the variances of these two indicators were largely explained by the general factor. The bifactor model was then modified by removing the two indicators from the specific factor. The modified model fit the data adequately, $\chi^{2}=609.92(d f=53, N=4,032)$, RMSEA $=$ .051 (CI: .047 to .055$)$, SRMR $=.030$, and CFI $=.982$.

As in Study 1, the items had stronger loadings on the general factor than on the specific factors, suggesting that most of their variances were shared with the general factor and that 
their specific factors were relatively weak. However, items of negative affect loaded equally strong on the general factor and its specific factor, indicating that its variance was split between the general factor and the specific factor and thus this factor was more distinct from other factors.

\subsubsection{A Second-Order Factor Model of Subjective Well-Being}

The second-order factor model of subjective well-being consisted of one second-order factor and three lower-order factors, good mood/PANAS positive affect, bad mood/ PANAS negative affect, and life satisfaction. The model fit the data adequately, $\chi^{2}=$ $843.67(d f=59, N=4,032)$, RMSEA $=.057$ (CI: .054 to .061$),$ SRMR $=.032$, and $\mathrm{CFI}=.975$.

All three components loaded strongly on the second-order factor, and the standardized factor loadings were $.88,-.79$, and .81 for good mood/PANAS positive affect, bad mood/ PANAS negative affect, and life satisfaction, respectively. These results suggest that there was a higher-order factor that represented the commonality shared by the components.

However, the corresponding bifactor model fit the data better than the second-order model, as there were small changes in RMSEA, SRMR, and CFI (RMSEA: .057 vs. .052; SRMR: .032 vs. .029; and CFI: .975 vs. .982), and the Chi-square difference was not trivial, $\Delta \chi^{2}=236.48, p<.001(\Delta d f=8, N=4,032)$.

\subsection{Testing a Bifactor Model of Psychological and Subjective Well-Being}

To test the competing views on the relations between PWB and SWB, we combined the psychological and subjective well-being items into an overall well-being model (Fig. 4). As in Study 1, the bifactor model of PWB and SWB consisted of one general factor (i.e., Global Well-Being) that captured the common ground shared by PWB and SWB. In addition, the bifactor model included four specific factors of PWB (i.e., autonomy, environmental mastery/self-acceptance, personal growth/purpose in life, and positive relations), and three specific factors of SWB (i.e., positive affect, negative affect, and life satisfaction). The factor loadings of the general and specific factors for the bifactor of PWB and SWB are presented in the "Appendix".

The model fit the data adequately, $\chi^{2}=8,444.78(d f=588, N=4,032)$, RMSEA $=$ .058 (CI: .056 to .059 ), SRMR $=.050$, and CFI $=.903$. The pattern of the loadings was similar to the one found in the separate bifactor model of PWB and of SWB.

\subsection{Testing a Second-Order Model of Psychological and Subjective Well-Being}

As in Study 1, the corresponding second-order model hypothesized that responses to the items from the psychological well-being and subjective well-being scales could be explained by four-lower order factors of PWB and three-lower order factors of SWB, and there was a higher-order factor that accounted for the variance shared by the lower-order factors. The model fit the data on the borderline, $\chi^{2}=9,842.41(d f=613, N=4,032)$, RMSEA $=.061$ (CI: .060 to .062$)$, SRMR $=.061$, and CFI $=.886$.

The bifactor models fit the data significantly better than the second-order model, $\Delta \chi^{2}=$ $1,397.63(\Delta \mathrm{df}=25), p<.001$, and there were also appreciable changes in RMSEA (.058 vs. .061), SRMR(.050 vs. .061), and CFI (.903 vs. .886), suggesting that the bifactor models provide a better approximation to the data. 


\subsection{Relations of General and Specific Factors of Well-Being to External Variables}

To examine whether the specific factors were uniquely associated with outcome variables beyond the general factor, the general and specific factors were used to predict the outcome variables simultaneously in the bifactor models. Given the exceptionally large sample size $(N=4,032)$, we used a more stringent significance value of $p<.001$. The results are presented in Table 2. As in Study 1, all outcome variables were treated as observed variables.

\subsubsection{Well-Being Measures}

The general well-being factor was related to all three measures of positive well-being: selfesteem, optimism, social well-being. Over and above the general well-being factor, autonomy was associated with self-esteem; mastery/acceptance was related to self-esteem and optimism; growth/purpose was related to self-esteem and social well-being; positive relations was related to social well-being; and negative affect was inversely related to selfesteem. In addition, the general well-being factor was negatively correlated with both measures of distress: depressed mood and somatic amplification. Positive affect was inversely related to depressed mood, and negative affect was associated with somatic amplification. These findings are consistent with the literature that high self-esteem, optimism, and social well-being are indicators of positive well-being, whereas high somatic amplification and depressed affect are indicators of negative well-being (Barsky et al. 1988; Keyes 1998; Lawton 1984; Lucas et al. 1996; Scheier et al. 2001).

Studies 1 and 2 shared three well-being related outcome variables: self-esteem, optimism and depressed mood. The general well-being factor was related to these measures in both studies. However, differences emerged with respect to the relations between the specific factors and the well-being measures. This discrepancy could be due to different measures used in the studies.

\subsubsection{Personality}

The general well-being factor was related to all measures of personality: neuroticism, extraversion, openness, conscientiousness, agreeableness, and agency. Independent of the general well-being factor, autonomy was related to extraversion, openness, conscientiousness, and agency; mastery/acceptance was related to extraversion, openness, and agency; growth/purpose was related to extraversion, openness, conscientiousness, agreeableness, and agency; positive relations was positively related to extraversion and agreeableness, but negatively related to agency; positive affect was related to extraversion, openness, conscientiousness, agreeableness, and agency; negative affect was related to neuroticism; and life satisfaction was related to agreeableness.

These results are generally consistent with the literature. For example, extraversion, neuroticism, and conscientiousness have been related to multiple aspects of well-being (DeNeve and Cooper 1998; Schmutte and Ryff 1997) and can differentiate those who scored high on both PWB and SWB from those who scored low on both (Keyes et al. 2002). These findings suggest that extraversion, neuroticism, and conscientiousness are related to the general construct of well-being. Also consistent with the literature, openness was related to growth/purpose and agreeableness was related to positive relations, even though openness and agreeableness were unrelated to other aspects of psychological well- 


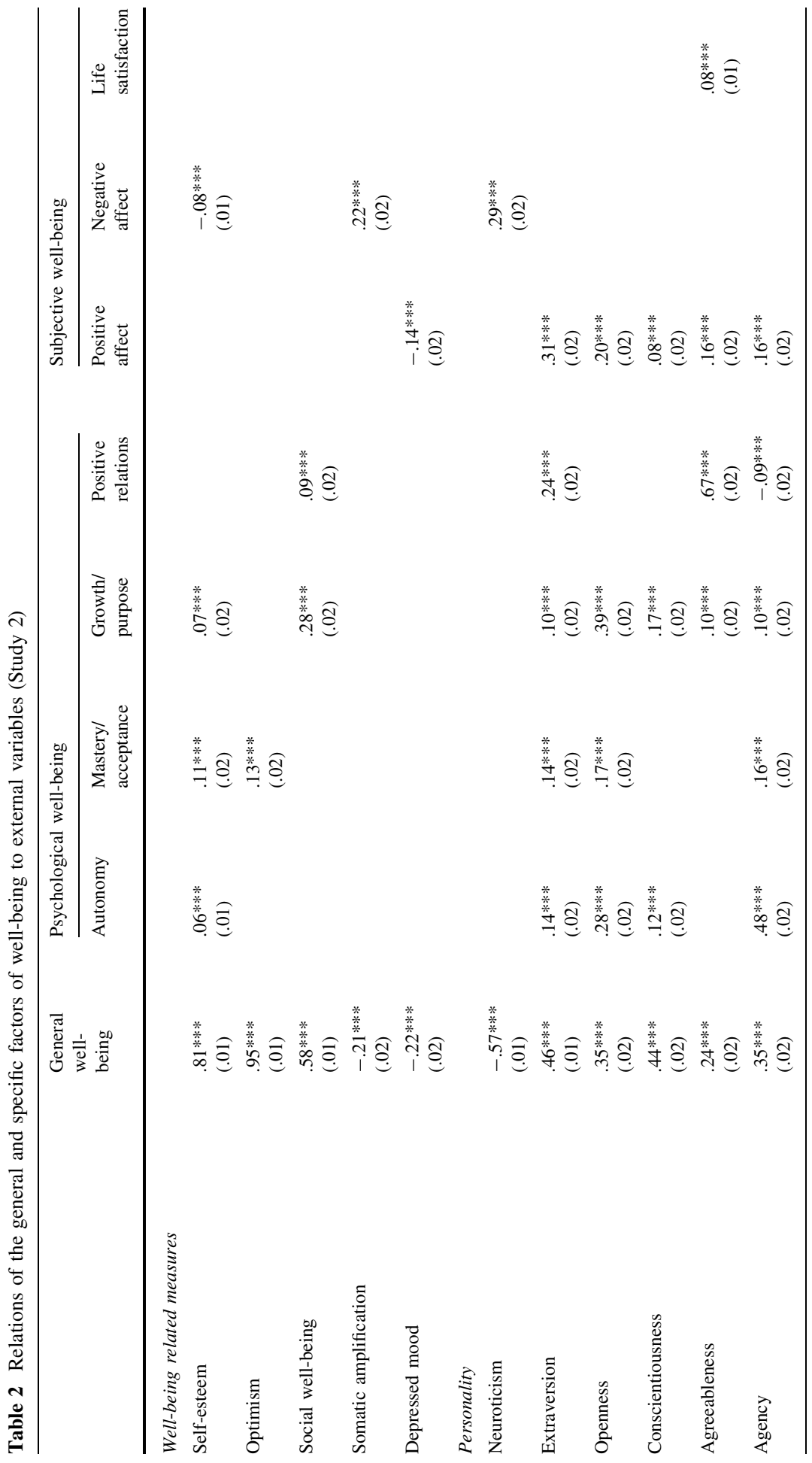




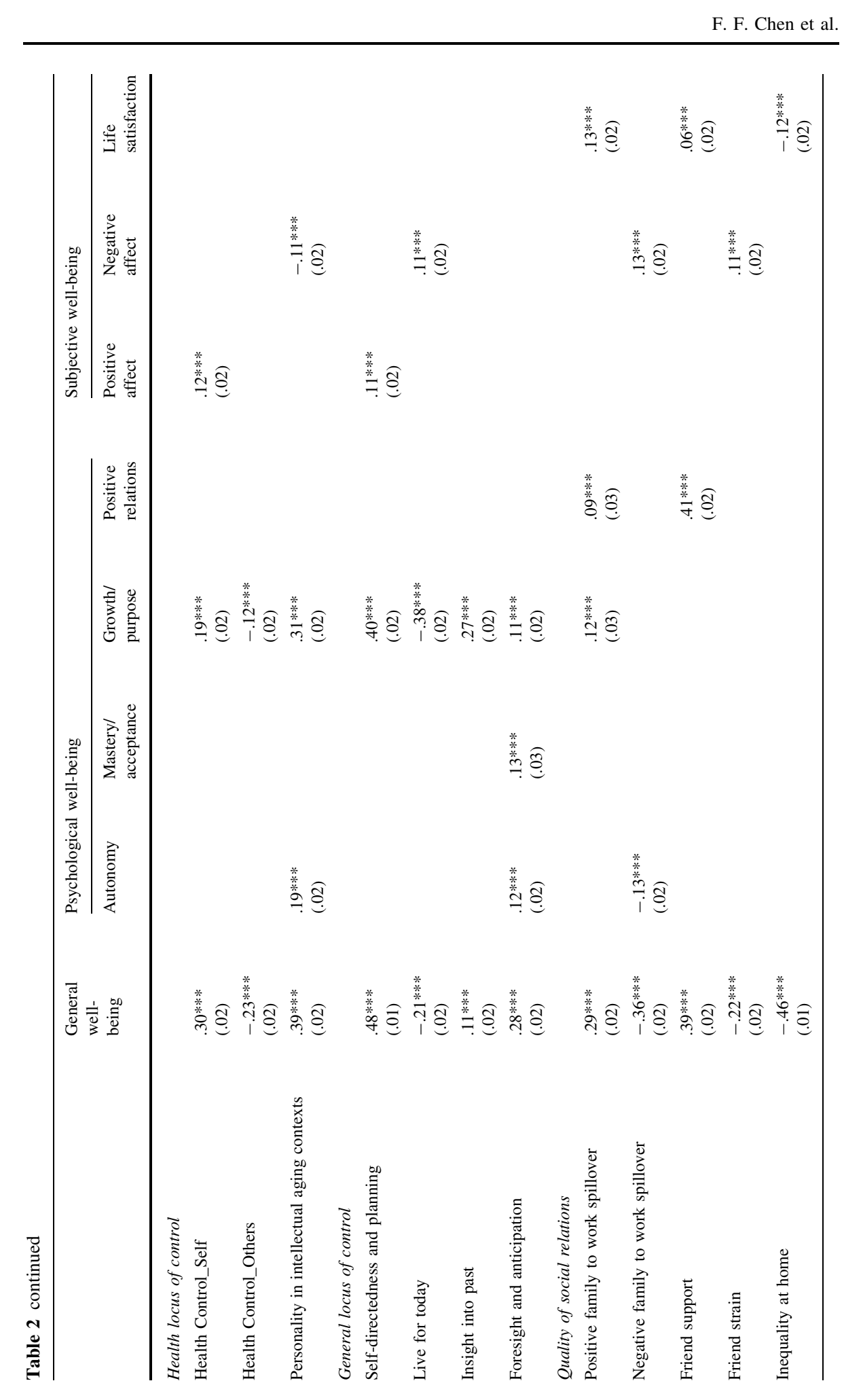

望 Springer 


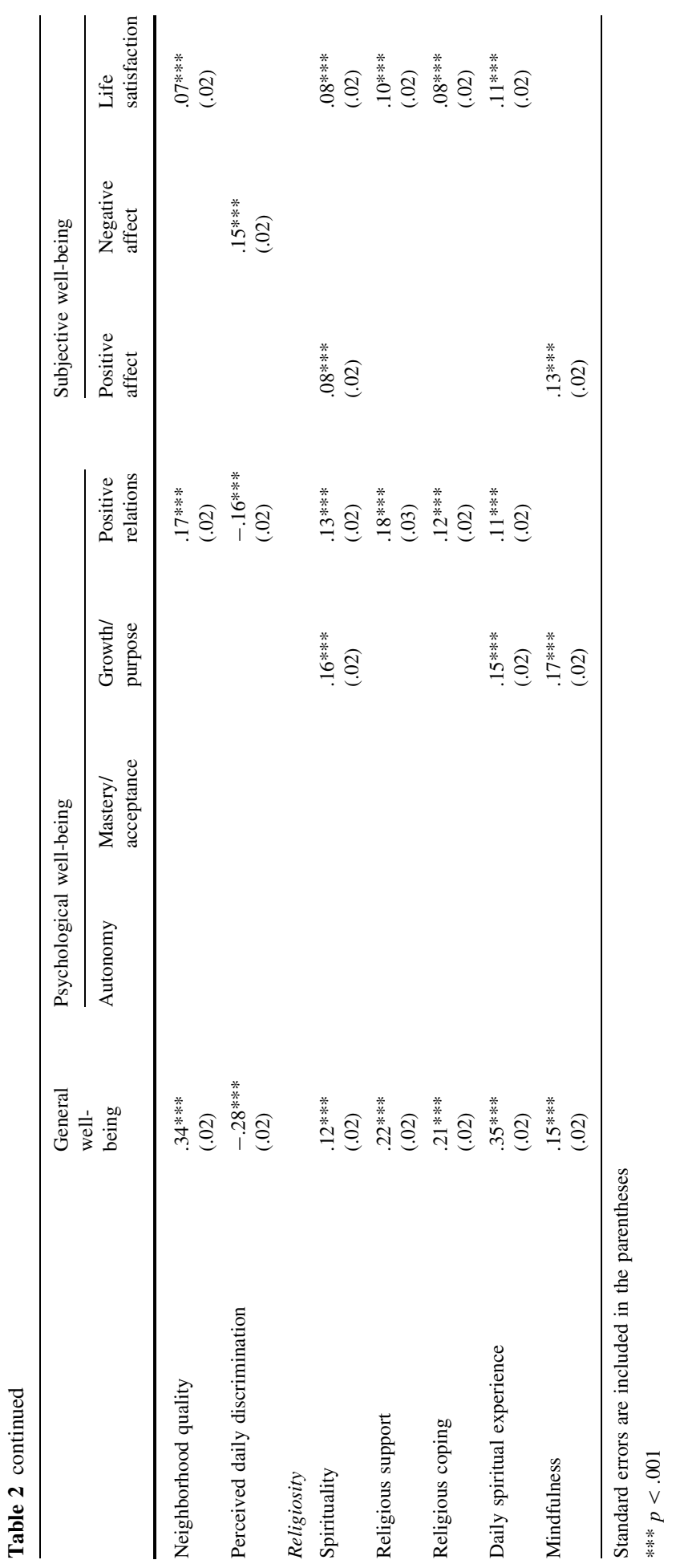


being (Schmutte and Ryff 1997). These findings suggest that openness and agreeableness are unrelated to the general construct of well-being.

\subsubsection{Health and Aging Related Locus of Control}

The general well-being factor was positively related to the sense of self-control and locus of control in aging, but negatively related to the sense of other-control in health. Independent of the general well-being factor, growth/purpose was related to both self-control and other-control. Positive affect was related to self-control. In addition, two domains of PWB (autonomy and growth/purpose) and one domain of SWB (negative affect) were related to locus of control in aging.

These findings reveal a positive association between the general well-being factor and health control by self and a negative association with health control by others. This is indirectly supported by Lachman and Prenda-Firth's (2004) findings that perceived selfcontrol in health is associated with fewer acute symptoms, chronic problems, and functional limitations, whereas believing that one's health is in the hands of doctors is associated with more acute symptoms, chronic problems, and functional limitations. These findings are also consistent with the literature that internal control beliefs promote wellbeing, whereas external control beliefs are associated with lower well-being (e.g., Lachman and Prenda-Firth 2004). Similarly, high scores on personality in intellectual aging contexts reflect internal control over intellectual aging, and thus it is beneficial to one's well-being.

\subsubsection{General Locus of Control: Planning and Making Sense of Past}

The general well-being factor was positively related to self-directedness and planning, insight into past, foresight and anticipation, and negatively related to living for today. Independent of the general well-being factor, autonomy and mastery/acceptance were related to foresight and anticipation; growth/purpose was positively related to selfdirectedness and planning, insight into past, and foresight and anticipation, but negatively related to living for today; positive affect was related to self-directedness and planning; and negative affect was related to living for today.

The relevant literature suggests that in Western cultures, planning for the future or future orientation is beneficial to one's well-being, whereas present orientation (e.g., living for today) is less healthy (McGrath and Tschan 2004; Prenda and Lachman 2001). Consistent with this position, our findings reveal that self-directedness and planning as well as foresight and anticipation (which captures behaviors of future orientation), are positively associated with the general well-being factor and with other positive domains of well-being (e.g., growth/purpose, positive affect). In contrast, living for today (which captures present orientation) is negatively associated with the general well-being factor and growth/purpose, but positively associated with negative affect. Interestingly, insight into past, which assesses a past orientation, is positively associated with growth/purpose. This may suggest that, for middle-aged individuals, a past-oriented perspective can be associated with more positive well-being. Given that the potential positivity of past orientation is often overlooked by the current literature, future studies should pay more attention to this issue. 


\subsubsection{Quality of Social Relations}

The general well-being factor was positively related to positive family to work spillover, friend support, and neighborhood quality, but negatively related to negative family to work spillover, friend strain, inequality at home, and perceived lifetime discrimination. Independent of the general well-being factor, autonomy was negatively related to negative family to work spillover; growth/purpose was related to positive family to work spillover; positive relations was related to positive family to work spillover, friend support, neighborhood quality, and negatively related to daily discrimination; negative affect was related to negative family to work spillover, friend strain, and daily discrimination; and life satisfaction was related to positive family to work spillover, friend support, inequality at home, and neighborhood quality.

These findings are consistent with previous research and theoretical expectations. For instance, Grzywacz (2000) found that positive family to work spillover was associated with psychological well-being, whereas negative family to work spillover was associated with lower well-being. With respect to friend support and strain, Whalen and Lachman (2000) reported that friend support was positively associated with positive affect and life satisfaction, yet negatively associated with negative affect. In contrast, friend strain was negatively associated with positive affect and life satisfaction. In addition, our findings are consistent with the theoretical expectation that social support (e.g., friend support) is beneficial to well-being, whereas social strain (e.g., friend strain) is detrimental to well-being (e.g., Cohen and Wills 1985). With respect to inequality at home, our findings are consistent with Ryff et al.'s (1999) finding that inequality at home was detrimental to well-being. With regard to neighborhood quality, Keyes's (1998) study suggested that it was associated with well-being, as it was correlated with a number of health-related variables (e.g., subjective physical health) and with social well-being. With respect to perceived lifetime discrimination, Ryff et al. (2004a) found that it was a significant predictor of every dimension of PWB. In addition, Werkuyten and Nekuee (1999) found that perceived discrimination was negatively associated with positive affect and life-satisfaction, and positively associated with negative affect.

\subsubsection{Religion}

The general well-being factor was positively related to spirituality, religious support, religious coping, daily spiritual experiences, and mindfulness. Independent of the general well-being factor, growth/purpose was related to spirituality, daily spiritual experience, and mindfulness; positive relations was related to spirituality, religious support, religious coping, and daily spiritual experiences; positive affect were related to spirituality and mindfulness; and life satisfaction was related to spirituality, religious support, religious coping, and daily spiritual experience.

These results are generally consistent with previous research. For instance, Ryff et al. (2004b) found that people who were high on PWB were more likely to be more religious. Ellison (1991) also concluded that individuals with strong religious faith had more life satisfaction, greater personal happiness, and fewer negative outcomes of traumatic events. Moreover, spirituality was related to personal growth and positive relations (Kirby et al. 2004; Wink and Dillon 2003). Taken together, these results suggest that spirituality is related to positive well-being. 
To summarize the findings thus far, the general well-being factor was related to all four types of external variables: other well-being measures, personality, locus of control, quality of social relations, and religion. Importantly, domains from both PWB and SWB had associations with these external variables, when the general well-being factor was partialled out. Specifically, growth/purpose (PWB) was related to other well-being measures, personality, locus of control, and religion, but not with quality of social relations except in the domain of positive family to work spillover. Positive relations (PWB) was related to personality, quality of social relations, and religion, but not with other well-being measures except for social well-being. Autonomy (PWB) was related to most measures of personality, one domain of other well-being measures, health related locus of control, general locus of control, and quality of social relations. Negative affect (SWB) was related to other well-being measures and quality of social relations, as well as one domain of personality measures and locus of control. Life satisfaction (SWB) was related to quality of social relations and religion.

\section{General Discussion}

The purpose of this paper was to use a bifactor model to evaluate two different views on the relations between psychological well-being and subjective well-being. The psychological well-being perspective argues that PWB examines human potential and the meaningful life, whereas SWB assesses happiness and the pleasant life, and thus PWB and SWB address different aspects of well-being (Keyes et al. 2002). However, the other camp proposes that PWB and SWB operate similarly at a higher level and complement each other in contributing to ultimate outcomes, and thus it is more meaningful to examine their similarities rather than differences (Kashdan et al. 2008). We examine these two views in two studies with a college student sample and a large nationally-representative community sample.

The bifactor model could help reconcile the two competing hypotheses and clarify the debate about the relations between PWB and SWB. On the one hand, findings from the bifactor model suggest that the overall constructs of PWB and SWB are strongly related to each other. This is because PWB and SWB form a general factor of global well-being, which captures the common ground shared by the two types of well-being. This finding provides support for the notion that PWB and SWB are conceptually related to each other. On the other hand, our findings also indicate that controlling for the general factor of global well-being, the components of PWB and of SWB form specific factors, which capture their unique variances. These specific factors are related to a wide range of external variables, independent of the general well-being factor. These findings provide support for the view that PWB and SWB are also distinct constructs, even though they are closely related at the general construct level.

Together, results from the bifactor model provide reasonable support for both views on the relations between PWB and SWB, that is the two constructs perspective and the two approaches perspective. When well-being is tested at general level of PWB and SWB (i.e., the general well-being factor), the two constructs are more similar than different. However, when well-being is examined with the specific components of PWB and SWB (i.e., the specific factors), partialling out the common variance shared with the general construct of global well-being, the two constructs are distinct with unique explanatory power of their own. Also as expected, the relative importance of aspirations and goals appear to have stronger associations with the dimensions of PWB than with the dimensions of SWB, 
independent of the general well-being, further demonstrating the differential predictive power of psychological and subjective well-being. The bifactor model allows us to test these two perspectives simultaneously. The findings suggest that there might be merit to both perspectives on the relations between psychological and subjective well-being, and thus it is more fruitful to study both types of well-being simultaneously.

\subsection{The Structure of Ryff Psychological Well-Being Scales}

Results from the bifactor models shed new light on the factor structure and the discriminant validity of Ryff's psychological well-being scales (Ryff 1989) in relation to psychological, physical, and social functioning outcomes. This widely used instrument is designed to measure six dimensions of psychological well-being. However, researchers have questioned the distinctiveness of the six components, as a six-factor model generally does not fit the data adequately (for review, see Abbott et al. 2006). For example, researchers found that the best fitting model for Ryff's scales is the one with a single second-order factor, comprised of four highly correlated components, and two correlated factors (i.e., autonomy and positive relations with others) (Abbott et al. 2006; Burns and Machin 2009, 2010). In another line of investigations, Springer and Hauser (2006) used CFA to test multiple competing models with the Ryff scales in several large data sets. Although a six-factor model fit the data better than a one-factor model, Springer and Hauser (2006) argue that the distinctive nature of the six dimensions is still in doubt. First, most of the latent factors are highly correlated with each other. Second, with a large sample size, a model with more factors would normally fit the data significantly better than a model with fewer factors, as model comparison is often based on the Chi-square difference test, which is a function of sample size. Ryff and Singer (2006) defended the six dimensions of psychological wellbeing by presenting evidence from factorial validity, psychological correlates, sociodemographic correlates, biological correlates, and intervention studies. Collectively, these studies indicate that the six dimensions tend to relate to external variables differentially, and they also show demographic variations. For example, environmental mastery tends to increase with age, but purpose in life and personal growth tend to decrease with age, whereas self-acceptance has little age variation.

There are two major limitations in previous studies. First, when testing the factorial structure of the Ryff scales, a six-factor model is often compared with several competing models, such as one-factor, three-factor, or four-factor models, and a Chi-square difference test is used to compare model fit. As noted earlier, theoretically, a regular CFA model with more factors tends to fit the data better than a model with fewer factors, and the Chi-square difference between the models will be larger when the sample size is particularly large. In contrast, the interpretation of a bifactor model is generally unaffected by sample sizes. A bifactor model tests whether there are meaningful specific factors (or dimensions) over and beyond the general factor. The existence of specific factors is indicated by factor loadings, similar to regression weights, which is relatively indifferent to sample size variations. Second, when testing the unique explanatory power of the scales, the unique variance of each dimension is often contaminated with the common variance shared with other dimensions (see McGregor and Little 1998; Vittersø 2003 for exceptions). Given the high correlations among the six dimensions, it is crucial to separate the unique contribution of each dimension from the general construct shared by the dimensions. Otherwise, it is unclear whether it is the general construct or specific components that are responsible for the effects, resulting in conceptual ambiguity. A bifactor model is well-suited for this purpose, as the general factor represents the common ground shared by the six dimensions, 
and the specific factors correspond to the residual contribution of each dimension. The general and specific factors can then be used to relate to external variables to test the incremental contribution of the specific factors, over and beyond the general factor.

For comparison purposes, we also tested the second-order model identified in previous studies, that is, a model with one higher-order factor comprised of four components and two other factors (i.e., autonomy and positive relations with others) (Abbott et al. 2006; Burns and Machin 2009, 2010). However, this model did not fit the data better than the full second-order factor model in which all six components were included as lower-order factors, suggesting that all six components form one general factor, consistent with our bifactor view.

The current studies suggest that there appear to be four, rather than six, dimensions in the Ryff scale. Environmental mastery and self-acceptance are highly correlated $(r=.90$ and .91 in Studies 1 and 2, respectively), as are purpose in life and personal growth ( $\mathrm{r}=.94$ and .97 in Studies 1 and 2, respectively). Consistent with this finding, the high correlation between the two pairs of dimensions has been found in other studies (e.g., Abbott et al. 2006; Burns and Machin 2009, 2010; Clarke et al. 2001; Ryff 1989; Ryff and Keyes 1995). Consequently, when all six dimensions were specified as the specific factors in the bifactor model, the model did not converge due to factor overextraction (Rindskopf 1984). The model only converged when the two sets of dimensions were combined. The specific factors of autonomy, growth/purpose, and positive relations with others are uniquely associated with a wide range of external variables, over and beyond the general well-being factor. However, the unique contribution of mastery/acceptance is limited because most of its variance is shared with the general factor. In contrast, autonomy, growth/purpose, and positive relations with others are distinct dimensions with unique explanatory power independent of the general construct of well-being.

It is plausible that the factorial structure of the Ryff psychological well-being scales varies depending on sample characteristics, such as gender, age, and socioeconomic class. Indeed, evidence suggests that different age groups respond to the items differently (Ryff and Singer 2006), and gender differences in item functioning have also been identified (Burns and Machin 2009, 2010). Therefore, for some groups, there may be six distinct dimensions, whereas for others there may be only four. This possibility may explain the discrepancy between the findings from the current study and those from Ryff and Singer's review (2006). Future studies should examine the factorial structure of PWB across diverse groups and perform measurement invariance tests when group comparisons are involved.

\subsection{The Structure of Subjective Well-Being}

Compared to the dimensionality of psychological well-being, there is more of a consensus regarding the structure of SWB. SWB consists of three components: the presence of positive mood, the absence of negative mood, and cognitive evaluation of life satisfaction (Diener and Lucas 1999). For example, Lucas et al. (1996) demonstrated the discriminant validity of the components of subjective well-being by using a multi-trait and multimethod. Recently, researchers tested the factorial structure of subjective well-being using multiple measures of positive affect, negative affect, and life satisfaction in three large data sets. A three-factor model fit the data the best, compared to a one-factor model (overall well-being) and two-factor model (affect and cognition) (Arthaud-Day et al. 2005). However, the approaches taken in the existing studies on subjective well-being share the same shortcomings as in the study of PWB. The bifactor model used in the current study reveals a general factor of subjective well-being that captures the common variance shared 
by the three components, plus three specific factors, corresponding to positive affect, negative affect, and life satisfaction. Most importantly, the three specific factors have unique explanatory power across a range of external variables, independent of the general factor of well-being. Results from the bifactor model demonstrate, in an unambiguous way, the distinctiveness of the three components of subjectively well-being.

\section{Conclusion}

The bifactor model provides a viable means for testing competing views on the relations between psychological and subjective well-being, because it simultaneously examines the overall well-being shared by the two types of well-being, as well as the specific factors that are unique to each. When well-being is assessed at the higher level, psychological wellbeing and subjective well-being appear to represent two perspectives on a general wellbeing construct (i.e., the two approaches view; Keyes et al. 2002). When well-being is evaluated with specific components, partialling out the common variance shared with the overall well-being factor, psychological well-being and subjective well-being seem to represent two distinguishable constructs (i.e., the two concepts view; Kashdan et al. 2008). The bifactor model serves as a useful tool for reconciling two opposing perspectives on the structure of well-being, as operationalized by the most commonly used measures of psychological and subjective well-being. Importantly, components from both psychological and subjective well-being show unique explanatory power, over and beyond the overall well-being, in understanding the relations of well-being to other well-being measures, personality, goals, locus of control, quality of social relations, and spirituality. These findings suggest that both perspectives on well-being have merit, depending on the level of analysis (i.e., general or specific).

\section{Appendix}

See Table 3.

Table 3 Standardized factor loadings of bifactor model of psychological and subjective well-being

\begin{tabular}{|c|c|c|c|c|c|c|c|c|}
\hline Parcels & $\begin{array}{l}\text { General } \\
\text { well-being }\end{array}$ & Autonomy & $\begin{array}{l}\text { Mastery/ } \\
\text { accept }\end{array}$ & $\begin{array}{l}\text { Growth/ } \\
\text { purpose }\end{array}$ & $\begin{array}{l}\text { Positive } \\
\text { relations }\end{array}$ & $\begin{array}{l}\text { Positive } \\
\text { affect }\end{array}$ & $\begin{array}{l}\text { Negative } \\
\text { affect }\end{array}$ & $\begin{array}{l}\text { Life } \\
\text { satisfaction }\end{array}$ \\
\hline Auto1 & $.42(.37)$ & $.58(.62)$ & & & & & & \\
\hline Auto2 & $.42(.39)$ & $.42(.38)$ & & & & & & \\
\hline Auto3 & $.48(.37)$ & $.55(.46)$ & & & & & & \\
\hline Auto4 & $.51(.43)$ & $.62(.34)$ & & & & & & \\
\hline Mast1 & $.74(.62)$ & & .28 & & & & & \\
\hline Mast2 & $.73(.63)$ & & $.12(.21)$ & & & & & \\
\hline Mast3 & $.51(.70)$ & & $.55(.06)$ & & & & & \\
\hline Mast4 & $.72(.68)$ & & .26 & & & & & \\
\hline Grow1 & $.36(.44)$ & & & $.41(.33)$ & & & & \\
\hline Grow2 & $.65(.53)$ & & & $.30(.55)$ & & & & \\
\hline Grow3 & $.55(.55)$ & & & $.09(.32)$ & & & & \\
\hline Grow4 & $.66(.57)$ & & & $.54(.34)$ & & & & \\
\hline
\end{tabular}


Table 3 continued

\begin{tabular}{|c|c|c|c|c|c|c|c|c|}
\hline Parcels & $\begin{array}{l}\text { General } \\
\text { well-being }\end{array}$ & Autonomy & $\begin{array}{l}\text { Mastery/ } \\
\text { accept }\end{array}$ & $\begin{array}{l}\text { Growth/ } \\
\text { purpose }\end{array}$ & $\begin{array}{l}\text { Positive } \\
\text { relations }\end{array}$ & $\begin{array}{l}\text { Positive } \\
\text { affect }\end{array}$ & $\begin{array}{l}\text { Negative } \\
\text { affect }\end{array}$ & $\begin{array}{l}\text { Life } \\
\text { satisfaction }\end{array}$ \\
\hline Relation1 & $.66(.61)$ & & & & $.40(.46)$ & & & \\
\hline Relation2 & $.71(.39)$ & & & & $.35(.30)$ & & & \\
\hline Relation3 & $.74(.66)$ & & & & $.23(.40)$ & & & \\
\hline Relation4 & $.69(.56)$ & & & & $.42(.47)$ & & & \\
\hline Purpose 1 & $.40(.67)$ & & & $.34(.20)$ & & & & \\
\hline Purpose2 & $.64(.45)$ & & & $.34(.37)$ & & & & \\
\hline Purpose 3 & $.66(.48)$ & & & $.32(.45)$ & & & & \\
\hline Purpose4 & $.71(.63)$ & & & $.34(.16)$ & & & & \\
\hline Accept 1 & $.78(.71)$ & & $.08(.32)$ & & & & & \\
\hline Accept 2 & $.80(.76)$ & & & & & & & \\
\hline Accept3 & $.83(.76)$ & & $(.12)$ & & & & & \\
\hline Accept 4 & $.73(.73)$ & & $.07(.41)$ & & & & & \\
\hline $\begin{array}{l}\text { PA1/ } \\
\text { Gmood1 }\end{array}$ & $.54(.65)$ & & & & & .42 & & \\
\hline $\begin{array}{l}\text { PA2/ } \\
\quad \text { Gmood2 }\end{array}$ & $.58(.67)$ & & & & & $.41(.31)$ & & \\
\hline $\begin{array}{l}\text { PA3/ } \\
\text { Gmood3 }\end{array}$ & $.57(.65)$ & & & & & .52 & & \\
\hline PA4/PA1 & $.55(.67)$ & & & & & $.61(.56)$ & & \\
\hline $\mathrm{PA} 5 / \mathrm{PA} 2$ & $.61(.65)$ & & & & & $.42(.56)$ & & \\
\hline $\begin{array}{l}\text { NA1/ } \\
\text { Bmood1 }\end{array}$ & $-.62(-.61)$ & & & & & & $.57(.51)$ & \\
\hline $\begin{array}{l}\text { NA2/ } \\
\text { Bmood2 }\end{array}$ & $-.58(-.49)$ & & & & & & $.50(.47)$ & \\
\hline $\begin{array}{l}\text { NA3/ } \\
\text { Bmood3 }\end{array}$ & $-.52(-.60)$ & & & & & & $.44(.54)$ & \\
\hline NA4/NA1 & $-.39(-.51)$ & & & & & & $.58(.58)$ & \\
\hline NA5/NA2 & $-.62(-.56)$ & & & & & & $.58(.54)$ & \\
\hline Life1 & $.56(.53)$ & & & & & & & $.55(.27)$ \\
\hline Life2 & $.62(.39)$ & & & & & & & $.61(.31)$ \\
\hline Life3 & $.70(.64)$ & & & & & & & $.53(.77)$ \\
\hline Life4 & .66 & & & & & & & .50 \\
\hline Life5 & .59 & & & & & & & .37 \\
\hline Variances & $1.78(1.60)$ & $.73(.59)$ & $.59(.30)$ & $.55(.60)$ & $.42(.78)$ & $.20(.22)$ & $.25(.13)$ & $1.25(1.37)$ \\
\hline
\end{tabular}

Loadings from Study 2 are presented in the parentheses

Auto autonomy, Mast mastery, Grow personal growth, Relation positive relations with others, Purpose purpose in life, Accept self-acceptance, PA positive affect, NA negative affect, Gmood good mood, Bmood bad mood, Life life satisfaction

\section{References}

Abbott, R. A., Ploubidis, G. B., Huppert, F. A., Kuh, D., Wadsworth, M. E. J., \& Croudace, T. J. (2006). Psychometric evaluation and predictive validity of Ryff's psychological wellbeing items in a UK cohort sample of women. Health and Quality of Life Outcomes, 4, 76.

Arthaud-Day, M. L., Rode, J. C., Mooney, C. H., \& Near, J. P. (2005). The subjective well-being construct: A test of its convergent, discriminant, and factorial validity. Social Indicators Research, 74, 445-476. 
Bagozzi, R. P., \& Edwards, J. R. (1998). A general approach for representing construct in organizational research. Organizational Research Methods, 1, 45-87.

Barsky, A. J., Goodson, J. D., Lane, R. S., \& Cleary, P. D. (1988). The amplification of somatic symptoms. Psychosomatic Medicine, 50, 510-519.

Beck, A. T., Steer, R. A., \& Brown, G. K. (1996). Manual for the beck depression inventory-II. San Antonio, TX: Psychological Corporation.

Bradburn, N. M. (1969). The structure of psychological well-being. Chicago: Aldine.

Briggs, S. R., \& Cheek, J. M. (1988). On the nature of self-monitoring: Problems with assessment, problems with validity. Journal of Personality and Social Psychology, 54, 663-678.

Burns, R. A., \& Machin, M. A. (2009). Investigating the structural validity of Ryff's Psychological WellBeing Scales across two samples. Social Indicators Research, 93, 359-375.

Burns, R. A., \& Machin, M. A. (2010). Identifying gender differences in the independent effects of personality and psychological well-being on two broad affect components of subjective wellbeing. Personality and Individual Differences, 48, 22-27.

Carver, C. S. (1989). How should multifaceted personality constructs be tested? Issues illustrated by self-monitoring, attributional style, and hardiness. Journal of Personality and Social Psychology, 56, 577-585.

Caspi, A., Roberts, B. W., \& Shiner, R. L. (2005). Personality development: Stability and change. Annual Review of Psychology, 56, 453-484.

Chen, F. F., Hayes, A., Carver, C. S., Laurenceau, J.-P., \& Zhang, Z. (2012). Modeling general and specific variance in multifaced constructs: A comparison of the bifactor model to other approaches. Journal of Personality, 80, 219-251.

Chen, F. F., West, S. G., \& Sousa, K. H. (2006). A comparison of bifactor and second-order models of quality of life. Multivariate Behavioral Research, 41, 189-225.

Clarke, P. J., Marshall, V. M., Ryff, C. D., \& Wheaton, B. (2001). Measuring psychological well-being in the Canadian Study of Health and Aging. International Psychogeriatrics, 13(Suppl. 1), 79-90.

Cohen, S., \& Wills, T. A. (1985). Stress, social support, and the buffering hypothesis. Psychological Bulletin, 98, 310-357.

Compton, W. C., Smith, M. L., Cornish, K. A., \& Qualls, D. L. (1996). Factor structure of mental health measures. Journal of Personality and Social Psychology, 71, 406-413.

Cutrona, C. E., \& Russell, D. W. (1987). The provisions of social relationships and adaptation to stress. In W. H. Jones \& D. Perlman (Eds.), Advances in personal relationships (Vol. 1, pp. 37-67). Greenwich, CT: JAI Press.

DeNeve, K. M., \& Cooper, H. (1998). The happy personality: A meta-analysis of 137 personality traits and subjective well-being. Psychological Bulletin, 124, 197-229.

DeYoung, C. G., Peterson, J. B., \& Higgins, D. M. (2002). Higher-order factors of the Big Five predict conformity: Are there neuroses of health? Personality and Individual Differences, 33, 533-552.

Diener, E. (1984). Subjective well-being. Psychological Bulletin, 95, 542-575.

Diener, E., Emmons, R. A., Larsen, R. J., \& Griffin, S. (1985). The satisfaction with life scale. Journal of Personality Assessment, 49, 71-75.

Diener, E., \& Lucas, R. E. (1999). Personality and subjective well-being: The foundations of hedonic psychology. In D. Kahneman \& E. Diener (Eds.), Well-being: The foundations of hedonic psychology (pp. 213-229). New York: Russell Sage Foundation.

Ellison, C. (1991). Religious involvement and subjective well-being. Journal of Health and Social Behavior, $32,80-89$.

Fetzer Institute/National Institute on Aging Working Group. (1999). Multidimensional measurement of religiousness/spirituality for use in health research: A report of the Fetzer Institute/National Institute on Aging Working Group. Kalamazoo, MI: Fetzer Institute.

Finch, J. F., \& West, S. G. (1997). The investigation of personality structure: Statistical models. Journal of Research in Personality, 31, 439-485.

Flugel, J. (1925). A quantitative study of feeling and emotion in everyday life. British Journal of Psychology, 15, 318-355.

Gaertner, L., Sedikides, C., \& Chang, K. (2008). On pancultural self-enhancement: Well-adjusted Taiwanese self-enhance on personally valued traits. Journal of Cross-Cultural Psychology, 39, 463-477.

Gallagher, M. W., Lopez, S. J., \& Preacher, K. J. (2009). The hierarchical structure of well-being. Journal of Personality, 77, 1025-1049.

Garfield, A. M., Ryff, C. D., \& Singer, B. (2001). Religion and health: Probing the connections. Poster presented at the 13th annual conference of the American Psychological Society, Toronto. 
Grouzet, F. M. E., Kasser, T., Ahuvia, A., Dols, J. M., Kim, Y., Lau, S., Ryan, R. M., Saunders, S., Schmuck, P., \& Sheldon, K. (2005). The structure of goals across 15 cultures. Journal of Personality and Social Psychology, 89, 800-816.

Grzywacz, J. G. (2000). Work-family spillover and health during midlife: Is managing conflict everything? American Journal of Health Promotion, 14, 236-243.

Gustafsson, J., \& Balke, G. (1993). General and specific abilities as predictors of school achievement. Multivariate Behavioral Research, 28, 407-434.

Hall, R. J., Snell, A. F., \& Foust, M. S. (1999). Item parceling strategies in SEM: Investigating the subtle effects of unmodeled secondary constructs. Organizational Research Methods, 2, 233-256.

Heine, S. J., \& Lehman, D. R. (1997). The cultural construction of self-enhancement: An examination of group-serving biases. Journal of Personality and Social Psychology, 72, 1268-1283.

Hull, J. G., Lehn, D. A., \& Tedlie, J. C. (1991). A general approach to testing multifaceted personality constructs. Journal of Personality and Social Psychology, 61, 932-945.

Kang, S., \& Shaver, P. R. (2004). Individual differences in emotional complexity: Their psychological implications. Journal of Personality, 72, 687-726.

Kashdan, T. B., Biswas-Diener, R., \& King, L. A. (2008). Reconsidering happiness: The costs of distinguishing between hedonics and eudaimonia. The Journal of Positive Psychology, 3, 219-233.

Kasser, T. (2002). The high price of materialism. Cambridge, MA: MIT Press.

Kasser, T., \& Ryan, R. M. (1993). A dark side of the American dream: Correlates of financial success as a central life aspiration. Journal of Personality and Social Psychology, 65, 410-422.

Kasser, T., \& Ryan, R. M. (1996). Further examining the American dream: Differential correlates of intrinsic and extrinsic goals. Personality and Social Psychology Bulletin, 22, 280-287.

Keyes, C. L. M. (1998). Social well-being. Social Psychology Quarterly, 61, 121-140.

Keyes, C. L. M., Shmotkin, D., \& Ryff, C. D. (2002). Optimizing well-being: The empirical encounter of two traditions. Journal of Personality and Social Psychology, 82, 1007-1022.

Kirby, S. E., Coleman, P. G., \& Daley, D. (2004). Spirituality and well-being in frail and nonfrail older adults. Journals of Gerontology. Series B, Psychological Sciences and Social Sciences, 59, 123-129.

Kline, R. B. (2011). Principles and practice of structural equation modeling (3rd ed.). New York, NY, USA: Guilford Press.

Lachman, M. E., Baltes, P. B., Nesselroade, J. R., \& Willis, S. L. (1982). Examination of personality-ability relationships in the elderly: The role of the contextual (interface) assessment mode. Journal of Research in Personality, 16, 485-501.

Lachman, M. E., \& Prenda-Firth, K. M. (2004). The adaptive value of feeling in control during midlife. In O. G. Brim, C. D. Ryff, \& R. C. Kessler (Eds.), How healthy are we? A national study of well-being at midlife (pp. 320-349). Chicago: University of Chicago Press.

Lachman, M. E., \& Weaver, S. L. (1998). Sociodemographic variations in the sense of control by domain: Findings from the MacArthur studies on midlife. Psychology and Aging, 13, 553-562.

Langer, E. J., \& Moldoveanu, M. (2000). The construct of mindfulness. Journal of Social Issues, 56, 1-9.

Lawton, M. P. (1984). The varieties of wellbeing. In C. Z. Malatesta \& C. E. Izard (Eds.), Emotion in adult development (pp. 67-84). Beverly Hills, CA: Sage.

Little, T. D., Cunningham, W. A., Shahar, G., \& Widaman, K. F. (2002). To parcel or not to parcel: Exploring the question, weighing the merits. Structural Equation Modeling, 9, 151-173.

Lucas, R. E., Diener, E., \& Sub, E. (1996). Discriminant validity of well-being measures. Journal of Personality and Social Psychology, 71, 616-628.

Markus, H. R., \& Kitayama, S. (1991). Culture and the self: Implications for cognition, emotion, and motivation. Psychological Review, 98, 224-253.

Marsh, H. W., Ellis, L. A., \& Craven, R. G. (2002). How do preschool children feel about themselves? Unraveling measurement and multidimensional self-concept structure. Developmental Psychology, 38, 376-393.

Marshall, G. N., Wortman, C. B., Kusulas, J. W., Hervig, L. K., \& Vickers, R. R., Jr. (1992). Distinguishing optimism from pessimism: Relations to fundamental dimensions of mood and personality. Journal of Personality and Social Psychology, 62, 1067-1074.

McCrae, R. R., \& Costa, P. T., Jr. (1992). Discriminant validity of NEO-PI-R facets. Educational and Psychological Measurement, 52, 229-237.

McGrath, J. E., \& Tschan, F. (2004). Temporal matters in social psychology. Washington, DC: American Psychological Association.

McGregor, I., \& Little, B. R. (1998). Personal projects, happiness, and meaning: On doing well and being yourself. Journal of Personality and Social Psychology, 74, 494-512.

Mroczek, D. K., \& Kolarz, C. M. (1998). The effect of age on positive and negative affect: A developmental perspective on happiness. Journal of Personality and Social Psychology, 75, 1333-1349. 
Muthén, L., \& Muthén, B. (1998-2009). Mplus user's guide. Los Angeles, CA: Muthén \& Muthén.

Ozer, D. J., \& Benet-Martínez, V. (2006). Personality and the prediction of consequential outcomes. Annual Review of Psychology, 57, 401-421.

Prenda, K. M., \& Lachman, M. E. (2001). Planning for the future: A life management strategy for increasing control and life satisfaction in adulthood. Psychology and Aging, 16, 206-216.

Reise, S. P., Morizot, J., \& Hays, R. D. (2007). The role of the bifactor model in resolving dimensionality issues in health outcomes measures. Quality of Life Research, 16(Suppl 1), 19-31.

Rindskopf, D. (1984). Structural equation models: Empirical identification, Heywood cases, and related problems. Sociological Methods \& Research, 13, 109-119.

Rindskopf, D., \& Rose, T. (1988). Some theory and applications of confirmatory second-order factor analysis. Multivariate Behavioral Research, 23, 51-67.

Rosenberg, M. (1965). Measurement of self-esteem. In M. Rosenberg (Ed.), Society and the adolescent self image (pp. 297-307). New York: Princeton University Press.

Rossi, A. S. (2001). Developmental roots of adult social responsibility. In A. S. Rossi (Ed.), Caring and doing for others: Social responsibility in the domains of family, work, and community (pp. 227-320). Chicago: University of Chicago Press.

Ryan, R. M., \& Deci, E. L. (2001). On happiness and human potentials: A review of research on hedonic and eudaimonic well-being. Annual Review of Psychology, 52, 141-166.

Ryan, R. M., Huta, V., \& Deci, E. L. (2008). Living well: A self-determination theory perspective on eudaimonia. Journal of Happiness Studies, 9, 139-170.

Ryff, C. D. (1989). Happiness is everything, or is it? Explorations on the meaning of psychological wellbeing. Journal of Personality and Social Psychology, 57, 1069-1081.

Ryff, C. D., \& Keyes, C. L. M. (1995). The structure of psychological well-being revisited. Journal of Personality and Social Psychology, 69, 719-727.

Ryff, C. D., Keyes, C. L. M., \& Hughes, D. L. (2004a). Psychological well-being in MIDUS: Profiles of ethnic/racial diversity and life-course uniformity. In O. G. Brim, C. D. Ryff, \& R. C. Kessler (Eds.), How healthy are we? A national study of well-being at midlife (pp. 398-422). Chicago: University of Chicago Press.

Ryff, C. D., Magee, W. J., Kling, K. C., \& Wing, E. H. (1999). Forging macro-micro linkages in the study of psychological well-being. In C. D. Ryff \& V. W. Marshall (Eds.), The self and society in aging processes (pp. 247-278). New York: Springer.

Ryff, C. D., \& Singer, B. H. (2006). Best news yet on the six-factor model of well-being. Social Science Research, 35, 1103-1119.

Ryff, C. D., \& Singer, B. H. (2008). Know thyself and become what you are: A eudaimonic approach to psychological well-being. Journal of Happiness Studies, 9, 13-39.

Ryff, C. D., Singer, B. H., \& Palmersheim, K. A. (2004b). Social inequalities in health and well-being: The role of relational and religious protective factors. In O. G. Brim, C. D. Ryff, \& R. C. Kessler (Eds.), How healthy are we? A national study of well-being at midlife (pp. 90-123). Chicago: University of Chicago Press.

Scheier, M. F., \& Carver, C. S. (1985). Optimism, coping and health: Assessment and implications of generalized outcome expectancies. Health Psychology, 4, 219-247.

Scheier, M. F., Carver, C. S., \& Bridges, M. W. (2001). Optimism, pessimism, and psychological wellbeing. In E. C. Chang (Ed.), Optimism and pessimism: Implications for theory, research, and practice (pp. 189-216). Washington, DC: American Psychological Association.

Schmutte, P. S., \& Ryff, C. D. (1997). Personality and well-being: Reexamining methods and meanings. Journal of Personality and Social Psychology, 73, 549-559.

Schuster, T. L., Kessler, R. C., \& Aseltine, R. H. (1990). Supportive interactions, negative interactions, and depressive mood. American Journal of Community Psychology, 18, 423-438.

Springer, K. W., \& Hauser, R. M. (2006). An assessment of the construct validity of Ryff's Scales of Psychological Well-Being: Method, mode, and measurement effects. Social Science Research, 35, 1120-1131.

Taylor, S. E., Lerner, J. S., Sherman, D. K., Sage, R. M., \& McDowell, N. K. (2003). Portrait of the selfenhancer: Well adjusted and well liked or maladjusted and friendless? Journal of Personality and Social Psychology, 84, 165-176.

Tett, R. P., Steele, J. R., \& Beauregard, R. S. (2003). Broad and narrow measures on both sides of the personality-job performance relationship. Journal of Organizational Behavior, 24, 335-356.

Vitters $\emptyset$, J. (2003). Flow versus life satisfaction: A projective use of cartoons to illustrate the difference between the evaluation approach and the intrinsic motivation approach to subjective quality of life. Journal of Happiness Studies, 4, 141-167. 
Wang, P. S., Berglund, P., \& Kessler, R. C. (2000). Recent care of common mental disorders in the United States: Prevalence and conformance with evidence-based recommendations. Journal of General Internal Medicine, 15, 284-292.

Waterman, A. S. (1993). Two conceptions of happiness: Contrasts of personal expressiveness (eudaimonia) and hedonic enjoyment. Journal of Personality and Social Psychology, 64, 678-691.

Watson, D., Clark, L. A., \& Tellegen, A. (1988). Development and validation of brief measures of positive and negative affect: The PANAS scales. Journal of Personality and Social Psychology, 54, 1063-1070.

Werkuyten, M., \& Nekuee, S. (1999). Subjective well-being, discrimination and cultural conflict: Iranians living in the Netherlands. Social Indicators Research, 47, 281-306.

Whalen, H. R., \& Lachman, M. E. (2000). Social support and strain from partner, family, and friends: Costs and benefits for men and women in adulthood. Journal of Social and Personal Relationships, 17, 5-30.

Williams, D. R., Yu, Y., Jackson, J. S., \& Anderson, N. B. (1997). Racial differences in physical and mental health: Socioeconomic status, stress, and discrimination. Journal of Health Psychology, 2, 335-351.

Wink, P., \& Dillon, M. (2003). Religiousness, spirituality, and psychosocial functioning in late adulthood: Findings from a longitudinal study. Psychology and Aging, 18, 916-924. 